ARTICLE

\title{
Spartan deficiency causes genomic instability and progeroid phenotypes
}

Reeja S. Maskey ${ }^{1, \star}$, Myoung Shin Kim ${ }^{2, \star}$, Darren J. Baker ${ }^{3}$, Bennett Childs ${ }^{1}$, Liviu A. Malureanu', Karthik B. Jeganathan ${ }^{1}$, Yuka Machida², Jan M. van Deursen ${ }^{1} \&$ Yuichi J. Machida ${ }^{2,4}$

Spartan (also known as DVC1 and C1orf124) is a PCNA-interacting protein implicated in translesion synthesis, a DNA damage tolerance process that allows the DNA replication machinery to replicate past nucleotide lesions. However, the physiological relevance of Spartan has not been established. Here we report that Spartan insufficiency in mice causes chromosomal instability, cellular senescence and early onset of age-related phenotypes. Whereas complete loss of Spartan causes early embryonic lethality, hypomorphic mice with low amounts of Spartan are viable. These mice are growth retarded and develop cataracts, lordokyphosis and cachexia at a young age. Cre-mediated depletion of Spartan from conditional knockout mouse embryonic fibroblasts results in impaired lesion bypass, incomplete DNA replication, formation of micronuclei and chromatin bridges and eventually cell death. These data demonstrate that Spartan plays a key role in maintaining structural and numerical chromosome integrity and suggest a link between Spartan insufficiency and progeria.

\footnotetext{
${ }^{1}$ Department of Biochemistry and Molecular Biology, Mayo Clinic, 200 First Street SW, Rochester, Minnesota 55905, USA. ${ }^{2}$ Department of Oncology, Mayo Clinic, 200 First Street SW, Rochester, Minnesota 55905, USA. ${ }^{3}$ Department of Pediatric and Adolescent Medicine, Mayo Clinic, 200 First Street SW, Rochester, Minnesota 55905, USA. ${ }^{4}$ Department of Molecular Pharmacology and Experimental Therapeutics, Mayo Clinic, 200 First Street SW, Rochester, Minnesota 55905, USA. * These authors contributed equally to this work. Correspondence and requests for materials should be addressed to Y.J.M. (email: machida.yuichi@mayo.edu).
} 
ninterrupted DNA replication is important for timely duplication of the genome before mitotic entry. However, the replication machinery may stall or slow down on replication stress caused by DNA lesions, limited nucleotide pools and repetitive DNA sequences ${ }^{1}$. Failure to deal with such replication stress could lead to genomic instability, which is associated with cancer and ageing ${ }^{2,3}$. In fact, genetic defects in replicative stress response have been implicated in genome instability syndromes that are characterized by increased cancer incidence and/or premature ageing phenotypes ${ }^{1}$. Although replication stress has been commonly linked to cancer susceptibility, accumulating evidence from mouse studies also supports the role of replication stress in premature ageing phenotypes and ageing of stem cells ${ }^{4-6}$.

Genomic DNA lesions are one of the common sources of replication stress. Because high-fidelity replicative polymerases cannot accommodate damaged bases in their active sites, unrepaired DNA lesions pose a risk of replication fork stalling, double-strand DNA breaks and cell death. To avoid such threat to genome stability, cells are equipped with a special replication system called translesion synthesis (TLS), which allows continuous replication across DNA lesions ${ }^{7,8}$. During TLS, monoubiquitination of proliferating cell nuclear antigen (PCNA), a sliding clamp for DNA polymerases, induces switching from replicative DNA polymerases to specialized TLS polymerases, thereby allowing bypass of DNA lesions. Although TLS protects replication forks from stalling at DNA lesions, it is potentially mutagenic because it utilizes error-prone DNA polymerases.

Spartan was recently identified as a novel regulator of TLS that guards against TLS-associated mutagenesis ${ }^{9-15}$. Spartan is recruited to DNA damage sites through the interaction with PCNA via its PIP (PCNA-interacting peptide) motif and the interaction of the zinc-finger domain UBZ4 with ubiquitin on PCNA or other proteins ${ }^{9-14}$. Several groups reported that Spartan promotes monoubiquitination of PCNA ${ }^{9,10,14}$, thereby facilitating recruitment of TLS polymerases, whereas other groups showed that Spartan recruits an ATP-dependent segregase p97 (also known as valosin-containing protein (VCP)) to the sites of TLS to facilitate dissociation of TLS polymerases ${ }^{12,13}$. In addition, our previous study linked Spartan to regulation of the error-prone TLS mechanism involving the DNA polymerase Pol $\zeta^{15}$. While these studies clearly implicated Spartan in TLS regulation, whether Spartan is required for TLS is unknown.

In this study, we create Sprtn-targeted mouse models and investigate the physiological importance of Spartan. We demonstrate essential roles of Spartan in lesion bypass, completion of DNA replication, genome stability and cell viability. Interestingly, Sprtn insufficiency causes senescence and progeria in mice. Our findings establish the critical role of Spartan in the cell cycle and the maintenance of genome integrity and provide the link between Spartan insufficiency and progeria.

\section{Results}

Sprtn knockout causes embryonic lethality in mice. To explore the physiological relevance of Spartan, we generated a series of mice with graded reduction in Spartan expression using hypomorphic $(\mathrm{H})$ and knockout (KO) Sprtn alleles that we generated by gene targeting (Fig. 1a,b). Intercrossing of Sprtn ${ }^{+1-}$ mice failed to produce Sprtn ${ }^{-I}$-live offspring and no Sprtn ${ }^{-1}-$ embryos were found from embryonic day (E) 7.5 to E13.5 (Table 1), suggesting that Sprtn KO in mice causes early embryonic lethality. To examine the effect of Sprtn KO on early embryogenesis, we isolated blastocysts at E3.5 and cultured them in vitro for 6 days. Genotyping was successful for all the blastocysts collected, and Sprtn ${ }^{-1}-$ blastocysts were obtained at normal Mendelian frequency (Fig. 1c; Table 2). However, Sprtn ${ }^{-1}$ - blastocysts failed to hatch and enlarge the inner cell mass when cultured in vitro (Fig. 1d; Table 2), indicating that death occurred prior at the implantation stage.

Effects of Sprtn KO on cell proliferation and survival. To further investigate the role of Sprtn at the cellular level, we generated a conditional Sprtn KO system in mouse embryonic fibroblasts (MEFs). Sprtn ${ }^{+/}, \operatorname{Sprtn}^{\mathrm{F} /+}$ and $\operatorname{Sprtn}^{\mathrm{F} /-} \mathrm{MEFs}$ were immortalized and transduced with retroviruses expressing Cre-ER ${ }^{\mathrm{T} 2}$. Treatment with 4-hydroxytamoxifen (4-OHT) resulted in excision of exon 2, efficiently converting the floxed allele to a KO allele (Fig. 2a). $\operatorname{Sprtn}^{\mathrm{F} /}-\mathrm{MEFs}$, but not Sprtn $^{+1+}$ and Sprtn ${ }^{\mathrm{F} /+}$ MEFs, showed markedly reduced proliferation and increased apoptosis after exposure to 4-OHT (Fig. 2b,c), suggesting that Sprtn is essential for cell proliferation and survival.

Cell cycle effects from the loss of Sprtn. To determine whether Sprtn KO has any effects on the cell cycle, we examined the cell cycle profile of MEFs with various genotypes by flow cytometry. A large portion of 4-OHT-treated Sprtn ${ }^{-}$- MEFs accumulated with 4C DNA content after treatment, whereas Sprtn ${ }^{+1+}$ and $S_{p r t n}{ }^{\mathrm{F} /}+$ cells were unaffected (Fig. 2d). To examine S-phase progression of $S_{p r t n}{ }^{-1}$ MEFs more closely, we performed 5-bromodeoxyuridine (BrdU) pulse-chase experiments, in which S-phase cells were pulse labelled with BrdU and chased in BrdUfree media every $2 \mathrm{~h}$ (Supplementary Fig. 1a). Sprtn ${ }^{-1}-$ MEFs initially progressed through $S$ phase at a similar rate to wild-type cells, but subsequently arrested with 4C DNA content at high rates (Supplementary Fig. 1b). These results suggest that Sprtn $^{-9-}$ cells exhibit normal S-phase progression, but accumulate in late $S$ or G2/M phases. A relatively small proportion of Sprtn ${ }^{-/-}$MEFs were positive for $\mathrm{p}-\mathrm{H} 3^{\text {Ser10 }}$, a well-established mitotic marker ${ }^{16,17}$, indicating that $\operatorname{Sprtn}^{-1-}$ cells accumulate before entry into mitosis (Supplementary Fig. 1c). Collectively, these results suggest that Spartan is essential for cell proliferation and faithful progression through late S and G2 phases.

The Spartan protein possesses multiple domains including SprT (a zinc metalloprotease-like domain), a SHP box (a p97interacting motif), a PIP box (a PCNA-interacting motif) and UBZ4 (a ubiquitin-binding domain) (Fig. 2e, top). We asked whether these domains are necessary for the function of Spartan in the cell cycle. Wild-type human Spartan, which was expressed at the similar level to endogenous Spartan in a human fibroblast cell line (Supplementary Fig. 2a), suppressed accumulation of cells in late S or G2 phase following loss of Sprtn in MEFs

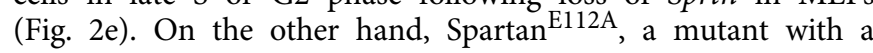
substitution in the putative active site of the metalloprotease-like domain SprT ${ }^{15}$, failed to rescue the cell cycle defect in Sprtn ${ }^{-1-}$ MEFs despite the similar expression level to wild-type Spartan (Fig. 2e; Supplementary Fig. 2a). In contrast, the ectopic expression of human Spartan ${ }^{\mathrm{PIP}^{\star}}$ and Spartan $\mathrm{UBZ}^{\star}$, which exhibit diminished interactions with PCNA and ubiquitin, respectively ${ }^{11}$, efficiently suppressed the cell cycle defect in Sprtn $^{-1-}$ MEFs (Supplementary Fig. 2b,d). Similarly, mouse Spartan ${ }^{S^{*}} P^{*}$, which harbours the mutations that diminish interaction with p97 (ref. 13), also suppressed the cell cycle defect in Sprtn ${ }^{-7}-$ MEFs as efficiently as wild-type Spartan (Supplementary Fig. 2c,e). Altogether, these results suggest that the putative active site of the SprT domain is essential for the cell cycle function of Spartan, while the PIP, UBZ and SHP domains are dispensable. 
a

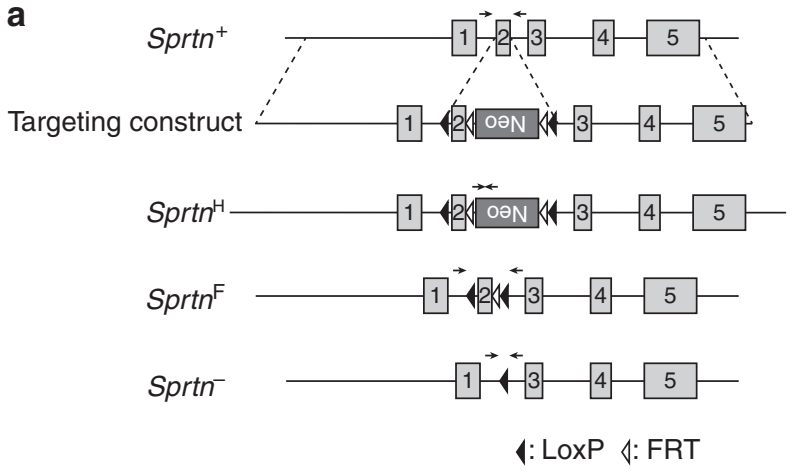

b

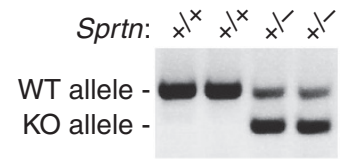

C Sprtn: $x^{x^{x}} x^{x^{*}} x^{\gamma^{\prime}} x^{\gamma^{\prime}} \lambda^{\prime} \lambda^{\prime}$

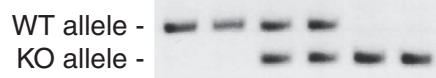

KO allele -

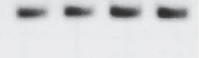

d

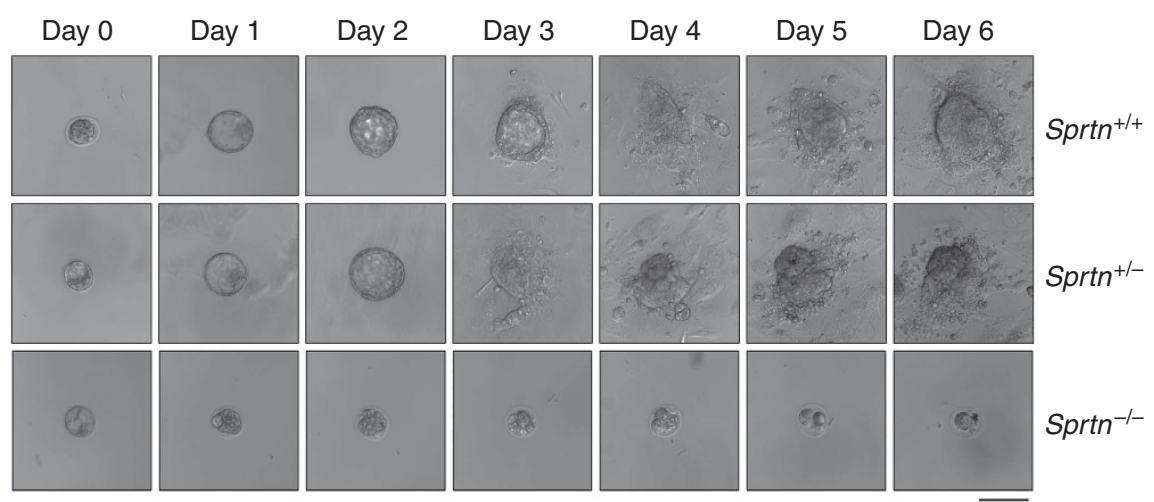

Figure 1 | Sprtn KO causes embryonic lethality. (a) Schematic of the mouse Sprtn gene and the targeted alleles. An inverted Neo cassette was inserted in the second intron with flanking FLP recognition target (FRT) sequences. LoxP sites were also inserted at the indicated positions. The floxed and KO alleles were created by crossing heterozygote mice with FLP and Cre-transgenic mice, respectively. Positions of genotyping primers are indicated by arrows. (b) PCR-based genotyping (at weaning) of wild-type and Sprtn heterozygote mice produced by intercrossing Sprtn $+/$ - . (c) PCR-based genotyping of wildtype, heterozygote and KO blastocysts. (d) Blastocysts from Sprtn $+/-$ intercrosses were cultured in vitro and observed by phase-contrast microscopy on 6 consecutive days. Representative images of Sprtn ${ }^{+/}$, Sprtn $^{+/-}$and Sprtn ${ }^{-/-}$blastocysts are shown. Scale bar, $100 \mu \mathrm{m}$.

\section{Table 1 | Genotypes of offspring and embryos from Sprtn $^{+} /-$intercrosses.}

\begin{tabular}{lcrcc}
$\begin{array}{l}\text { Developmental } \\
\text { stages }\end{array}$ & Sprtn & & & \\
\hline E3.5 & $6(24.0 \%)$ & $13(52.0 \%)$ & $6(24.0 \%)$ & 25 \\
E7.5 & $5(25.0 \%)$ & $15(75.0 \%)$ & 0 & 20 \\
E9.5 & $5(26.3 \%)$ & $14(73.7 \%)$ & 0 & 19 \\
E11.5 & $7(31.8 \%)$ & $15(68.2 \%)$ & 0 & 22 \\
E13.5 & $6(30.0 \%)$ & $14(70.0 \%)$ & 0 & 20 \\
P21 & $85(41.5 \%)$ & $120(58.5 \%)$ & 0 & 205 \\
\hline E, embryonic day; P, postnatal day. & & & \\
\hline
\end{tabular}

Loss of Spartan causes DNA damage and checkpoint activation. To determine the cause of the cell cycle defect in Sprtn $^{-1-}$ MEFs, we asked whether Spartan deficiency engages the DNA damage response pathway. $\gamma \mathrm{H} 2 \mathrm{AX}$ foci, a marker of DNA damage ${ }^{18}$, markedly increased in $\operatorname{Sprtn}^{\mathrm{F} /-}$ MEFs after 4-OHT treatments, but not in Sprtn $+T^{+}$and Sprtn $^{\mathrm{F} /}+$ MEFs (Fig. 3a). Consistent with increased DNA damage, Sprtn ${ }^{-1}$ MEFs showed high rates of doublestrand DNA breaks as measured by immunostaining of the DNA recombination protein Rad51 (Fig. 3b) and profound activation of the checkpoint kinase Chk2 (Fig. 3c). Thus, loss of Sprtn in MEFs seemingly induces DNA damage, most likely DNA breaks, leading to activation of the DNA damage checkpoint.
Table 2 | In vitro development of blastocysts.

\begin{tabular}{|cccc|} 
Genotype & $\begin{array}{c}\text { Number of } \\
\text { blastocysts }\end{array}$ & \multicolumn{2}{c|}{ Number of blastocysts presenting } \\
\cline { 3 - 4 } & & $\begin{array}{c}\text { Zona hatching } \\
\text { at day 3 }\end{array}$ & $\begin{array}{c}\text { ICM outgrowth } \\
\text { at day } \mathbf{6}\end{array}$ \\
\hline Sprtn $+/+$ & 6 & 6 & 6 \\
Sprtn $+/-$ & 13 & 12 & 12 \\
Sprtn & $-/-$ & 0 & 0 \\
\hline ICM, inner cell mass. & 6 & & \\
\hline
\end{tabular}

Depletion of Spartan causes genomic instability. The elevated levels of DNA damage accompanied by checkpoint activation in Sprtn ${ }^{-1}$ MEFs prompted us to assess whether loss of Spartan induces genomic instability. Microscopic analysis of $4^{\prime}, 6-$ diamidino-2-phenylindole (DAPI)-stained MEFs revealed that a substantial fraction of mitotic Sprtn ${ }^{-}-$MEFs exhibited chromatin bridges and micronuclei, structures that have been associated with unresolved replication intermediates and unrepaired DNA breaks ${ }^{19}$ (Fig. $4 \mathrm{a}-\mathrm{c}$ ). In addition, these MEFs had increased numbers of 53BP1 nuclear bodies that signify incomplete DNA replication ${ }^{20,21}$ (Fig. 4d). These data raise the possibility that the genome of Sprtn-deficient cells is subject to under-replication. Consistent with this interpretation, the vast majority of chromosomal abnormalities observed in the mitotic spreads of Sprtn ${ }^{-1-}$ MEFs were chromosome gaps, which might 
a

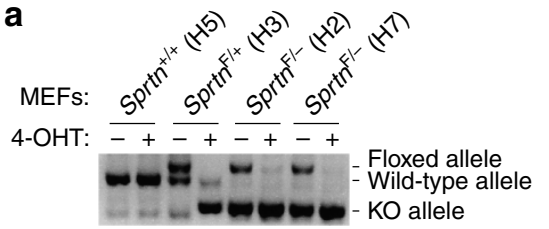

C

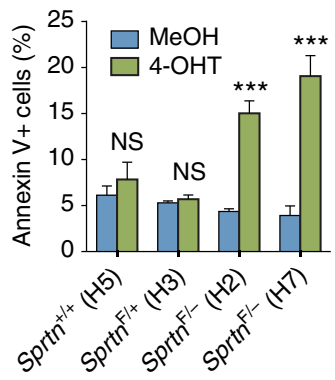

b
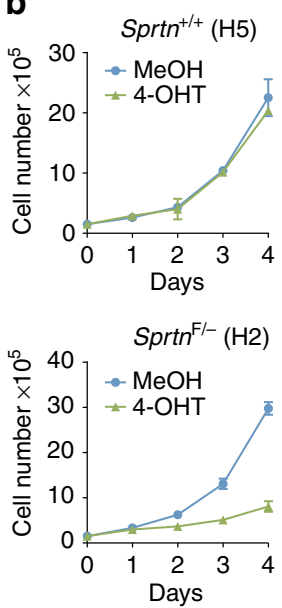
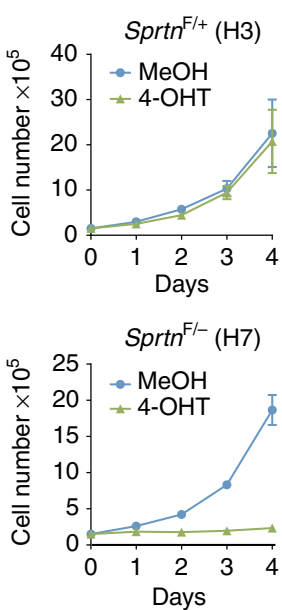

d

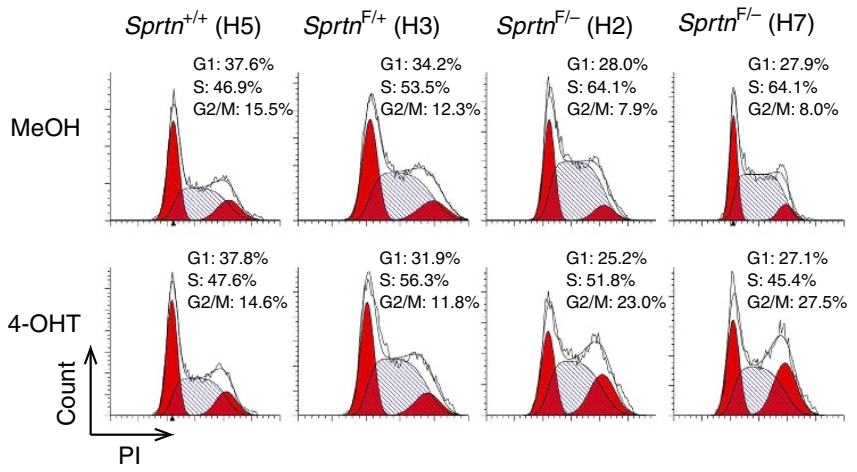

e
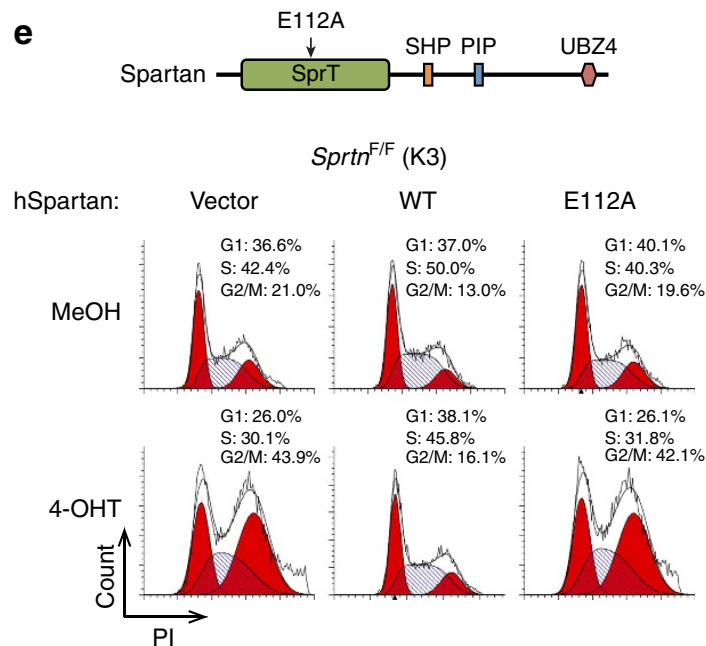

Figure 2 | Sprtn KO causes impaired cell proliferation and cell death. (a) PCR-based genotyping of Sprth alleles in the indicated MEF lines after $48 \mathrm{~h}$ treatment with $\mathrm{MeOH}$ or $2 \mu \mathrm{M} 4-\mathrm{OHT}$. (b) Proliferation of Sprtn-targeted MEFs. Cells treated with $\mathrm{MeOH}$ or $4-\mathrm{OHT}$ for $48 \mathrm{~h}$ were seeded and cell numbers were counted at the indicated time points. Values are mean \pm s.d. of three independent experiments. (c) Analyses of apoptosis in Sprtn-targeted MEFs. Two days after the completion of $48 \mathrm{~h}$ treatment with $\mathrm{MeOH}$ or $4-\mathrm{OHT}$, cells were stained with Annexin $\mathrm{V}$ and $\mathrm{PI}$ and analysed by flow cytometry. Values are mean \pm s.d. of three independent experiments. NS, not significant; ${ }^{\star \star \star} P<0.001$ (two-tailed unpaired $t$-test). (d) Cell cycle profiling of Sprtn-targeted MEFs. The indicated MEF lines were treated with $\mathrm{MeOH}$ or $4-\mathrm{OHT}$ for $48 \mathrm{~h}$. Two days later, cells were stained with PI and analysed by flow cytometry. (e) Cell cycle profiling of Sprtn ${ }^{\mathrm{F} / \mathrm{F}}$; Cre-ER ${ }^{T 2} \mathrm{MEFs}(\mathrm{K} 3)$ expressing wild-type human Spartan or the E112A mutant after $48 \mathrm{~h}$ treatment with $\mathrm{MeOH}$ or $4-\mathrm{OHT}$.

represent under-replicated regions (Fig. 4e,f). In summary, these results suggest that Spartan is crucial for maintaining genome integrity.

Lesion bypass defects in Sprtn ${ }^{-/-}$cells. To examine the effect of Sprtn inactivation on DNA replication more directly, we measured movement of replication forks in Sprtn ${ }^{-1}$ MEFs using DNA fiber assays, in which replication tracts were sequentially labelled with the thymidine analogues IdU and CldU (Fig. 5a). Lengths of CldU-labelled DNA in Sprtn ${ }^{-1}$ MEFs were not significantly different from those of Sprtn $+1+$ MEFs (Fig. 5b), suggesting that the majority of replication forks are not affected by Spartan loss, an observation consistent with the normal S-phase progression in Sprtn ${ }^{-1}$ cells (Supplementary Fig. 1b).

Given that Sprtn ${ }^{-1-}$ cells have mostly intact replication forks but still accumulate in late S/G2 phases accompanied by underreplication phenotypes, we hypothesized that Spartan might be important for DNA replication under stress, for example, imposed by endogenously created DNA lesions. Previous reports have indeed linked Spartan's function to TLS $^{9-15}$, although whether Spartan is necessary for the bypass of DNA lesions during DNA replication has not been established. We therefore tested the requirement of Spartan for lesion bypass during DNA replication. DNA fiber assays were performed with ultraviolet light exposure, which introduces lesions acted on by TLS, between IdU and CldU labelling (Fig. 5a). Lesion bypass efficiency is expressed as elongation ratios (CldU/IdU), which would be reduced with lesion bypass defects. Strikingly, Sprtn KO in MEFs caused reduced fork progression at ultraviolet-induced lesions (Fig. 5c), suggesting that Spartan is important for ultravioletinduced lesion bypass. We also examined whether Spartan plays a role in the stability of stalled forks by measuring replication fork restart after hydroxyurea (HU) treatments (Supplementary Fig. 3a). Sprtn KO did not increase the amount of collapsed forks on HU treatments (Supplementary Fig. 3b), suggesting that Spartan is not necessary for replication restart after fork stalling. 
a
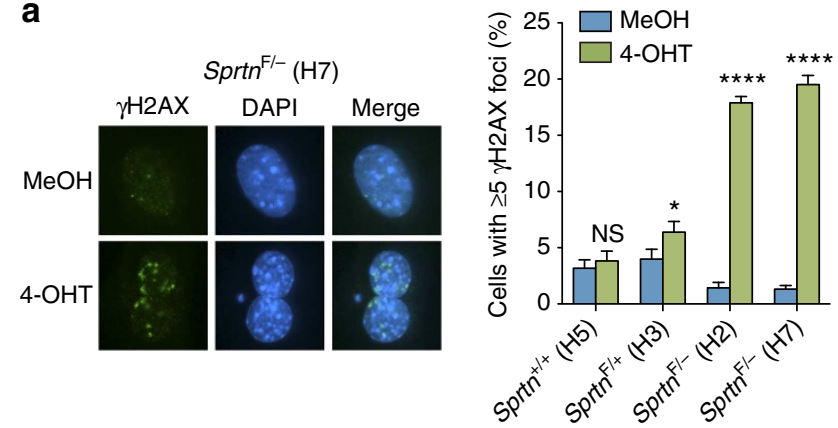

b
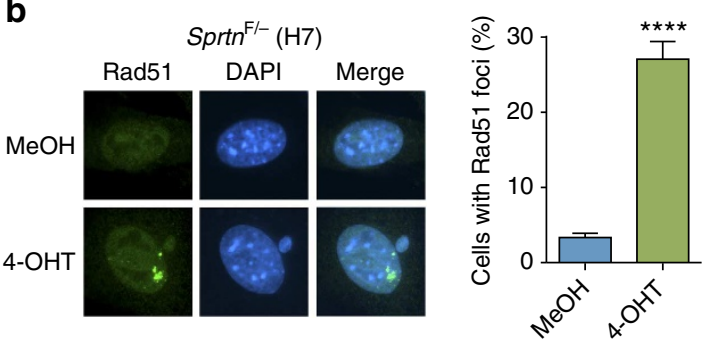

C

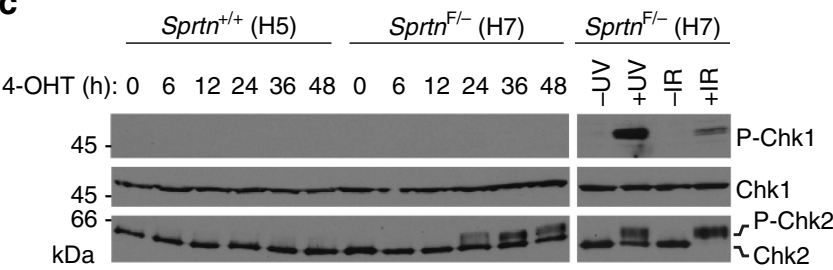

Figure 3 | Sprtn KO causes DNA damage and checkpoint activation. (a) $\gamma \mathrm{H} 2 \mathrm{AX}$ focus formation. The indicated MEFs treated with $\mathrm{MeOH}$ or $4-\mathrm{OHT}$ for $48 \mathrm{~h}$ were stained with anti- $\gamma \mathrm{H} 2 \mathrm{AX}$. At least 300 cells were scored for $\gamma \mathrm{H} 2 \mathrm{AX}$ foci and percentages of cells with 5 or more foci are shown. Values are mean \pm s.d. of three independent experiments. NS, not significant; ${ }^{\star} P<0.05$; ${ }^{\star \star \star \star} P<0.0001$ (two-tailed unpaired $t$-test). (b) Rad51 focus formation. The indicated MEFs were stained with anti-Rad51 after $48 \mathrm{~h}$ treatment with $\mathrm{MeOH}$ or $4-\mathrm{OHT}$. At least 300 cells were scored for Rad51 foci. Experiments were performed in triplicate and mean \pm s.d. is shown. ${ }^{\star \star \star \star} P<0.0001$ (two-tailed unpaired $t$-test). (c) Western blot analyses of phospho-Chk1 and Chk2. The indicated MEFs were treated with 4-OHT and harvested at various time points. $\mathrm{Sprth}^{\mathrm{F} /-}(\mathrm{H} 7)$ cells treated with ultraviolet $\left(40 \mathrm{~J} \mathrm{~m}^{-2}\right.$ ) or ionizing radiation (10 Gy) are shown as positive controls for checkpoint kinases activation. Chk1 is used as a loading control. P-Chk1, phospho-Chk1 (Ser345); P-Chk2, phospho-Chk2.

Uncropped blots are shown in Supplementary Fig. 7.

Next we assessed the requirement of the Spartan domains for the bypass of ultraviolet-induced lesions by re-expressing Spartan mutants in conditional Sprtn KO MEFs. The lesion bypass defect in $\operatorname{Sprtn}^{-1-}$ cells was rescued by the introduction of wild-type human Spartan, but not the mutant that harbours the E112A mutation in the putative active site (Fig. $5 \mathrm{~d}$ ), suggesting that the role of Spartan in lesion bypass requires an intact SprT domain. On the other hand, the $\mathrm{PIP}^{\star}, \mathrm{UBZ}^{\star}$ or $\mathrm{SHP}^{\star}$ mutants of Spartan exhibited partially diminished abilities to rescue the lesion bypass defects in Sprtn ${ }^{-1-}$ MEFs (Fig. 5e,f). Taken together, these results suggest that Spartan is dispensable for the replication of the bulk of the genome, but is crucial for replication past DNA damage. This function of Spartan in lesion bypass depends on the putative active site of the SprT domain, but only partially on the PIP, UBZ4 and SHP domains.

To obtain more insight into the role of Spartan in lesion bypass, we examined the effect of Sprtn KO on PCNA ubiquitination in response to ultraviolet irradiation and dissociation of Pol $\eta$ from ultraviolet-induced DNA damage sites, the two processes that have been reported to be impaired in Spartandepleted human cells $9,10,12-14$. PCNA ubiquitination after ultraviolet irradiation was largely intact in $\operatorname{Sprtn}^{-1-}$ cells (Supplementary Fig. 3c), suggesting that Spartan is not absolutely necessary for ultraviolet-induced PCNA ubiquitination. On the other hand, in agreement with previous reports ${ }^{12,13}$, we observed prolonged retention of enhanced green fluorescent protein (EGFP)-Pol $\eta$ foci after ultraviolet irradiation in Sprtn $^{-1}-$ cells (Supplementary Fig. 3d), although it remains to be determined whether this is due to a failure to extract Pol $\eta$ from DNA damage sites as proposed previously ${ }^{12,13}$ or it reflects the lesion bypass defects we report in this study (Fig. 5c).

Growth defects and genome instability in $\operatorname{Sprtn}^{\mathrm{H} /}-$ cells. Finally, we examined the effect of Sprtn insufficiency by producing Sprtn hypomorphic mice. The targeted Sprtn ${ }^{\text {Neo }}$ allele is hypomorphic (hereafter referred to as $S p r t n^{\mathrm{H}}$ ), producing wildtype mRNAs at reduced levels due to the cryptic exon in the $\mathrm{Neo}$ cassette $^{22}$ (Supplementary Fig. 4a). In contrast to Sprtn ${ }^{-1-}$ MEFs, Sprtn $\mathrm{H} /-$ MEFs, which contain one $\mathrm{KO}$ and one hypomorphic allele that produce reduced amounts of wild-type Spartan, were viable, but proliferated at reduced rates (Supplementary Fig. 4b-d). Furthermore, Sprtn ${ }^{\mathrm{H} /}-$ MEFs had increased rates of aneuploidy and micronuclei (Supplementary Fig. 4e,f; Supplementary Table 1), indicating that, in addition to structural chromosome damage, Spartan insufficiency leads to numerical chromosome instability.

Growth defects and genomic instability in $\operatorname{Sprtn}^{\mathrm{H} / \mathrm{H}}$ mice. Although no viable Sprtn $\mathrm{H}$ / - offspring were found in crossing of $S_{\text {Sptn }}{ }^{+1-}$ and Sprtn ${ }^{+/ \mathrm{H}}$ mice, Sprtn ${ }^{\mathrm{H} / \mathrm{H}}$ mice were born at near Mendelian frequency from Sprtn ${ }^{+/ \mathrm{H}}$ breeding pairs $\left(S_{p r t n}{ }^{+1+}\right.$, Sprtn $^{+/ \mathrm{H}}$ and $\operatorname{Sprtn}^{\mathrm{H} / \mathrm{H}}$ at 26.6, 53.3 and 20.1\%, respectively), despite substantially reduced Sprtn expression (Fig. 6a,b). At weaning, Sprtn $\mathrm{H}^{\mathrm{H}}$ mice appeared healthy but were overtly smaller than control littermates. Dwarfism was observed in both sexes and persisted as $S p r t n^{\mathrm{H} / \mathrm{H}}$ mice developed to adulthood (Fig. 6c). To investigate in more detail the effects of Sprtn insufficiency in $S_{p r t n} \mathrm{H} / \mathrm{H}$ mice, we isolated primary lung fibroblasts and prostate epithelial cells from Sprtn $+1+$ and Sprtn $\mathrm{H} / \mathrm{H}$ mice. Sprtn expression was reduced to less than $10 \%$ in the Sprtn $^{\mathrm{H} / \mathrm{H}}$ cells (Supplementary Fig. 5a,b). Sprtn ${ }^{\mathrm{H} / \mathrm{H}}$ lung fibroblasts showed elevated structural and numerical chromosomal instabilities, as evidenced by increased rates of $\gamma \mathrm{H} 2 \mathrm{AX}$ foci, aneuploidy and micronuclei (Fig. 6d,e; Table 3). In addition, $\operatorname{Sprtn}^{\mathrm{H} / \mathrm{H}}$ lung fibroblasts displayed defects in fork progression at ultraviolet-induced lesion, which was also confirmed in $\operatorname{Sprtn}^{\mathrm{H} / \mathrm{H}}$ prostate epithelial cells (Fig. 6f; Supplementary Fig. 5c). Taken together, these results indicate that cells from Sprtn hypomorphic mice exhibit genome instability and lesion bypass defects.

Reduced expression of Sprtn causes accelerated ageing in mice. As young adults, $\operatorname{Sprtn}^{\mathrm{H} / \mathrm{H}}$ mice exhibited no overt phenotypes other than dwarfism. However, by 12 months of age, all Sprtn ${ }^{\mathrm{H} / \mathrm{H}}$ mice (seven out of seven mice) had developed lordokyphosis (concavity in the curvature of the lumbar and cervical spine), cataracts and cachexia (Fig. 7a,b), three phenotypes often seen in mouse models of progeria ${ }^{23-25}$. The total fat mass and percentage of body fat of these mice were dramatically reduced (Fig. 7c). Indepth analysis of individual fat depots revealed that the relative weights of the paraovarian, inguinal adipose tissue (IAT), perirenal and subscapular adipose tissue were all significantly reduced in size (Fig. 7 c). Consistent with fat tissue atrophy, fat 
a

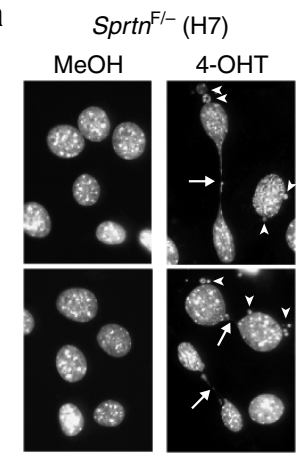

d

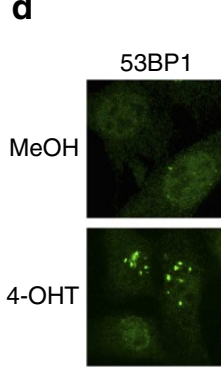

Sprth $^{\mathrm{F} /}(\mathrm{H7})$
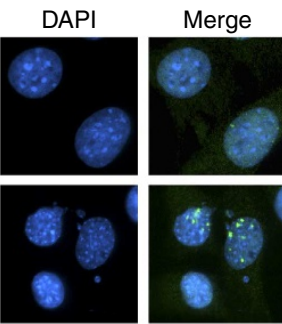

e

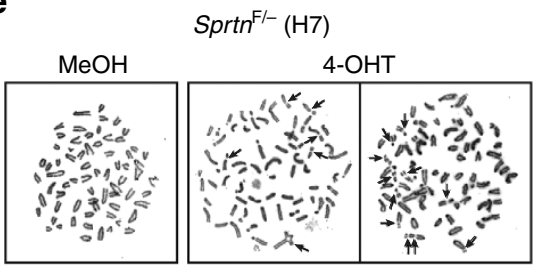

b

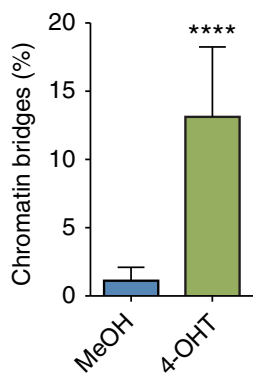

c

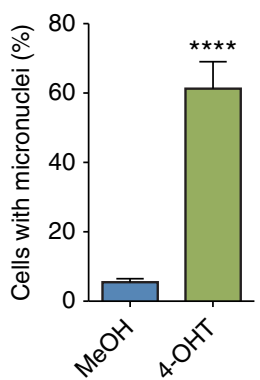

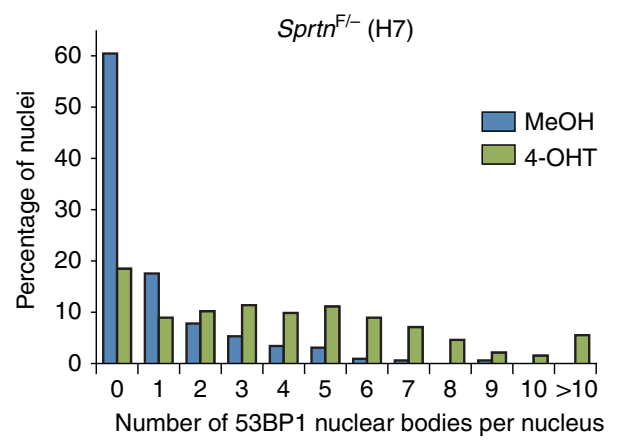

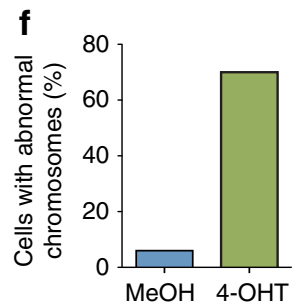

Figure 4 | Genome instability in Sprtn KO MEFs. (a) Images showing chromatin bridges (arrows) and micronuclei (arrowheads) in Sprtn ${ }^{\mathrm{F} /}-\mathrm{MEFs} \mathrm{treated}$ with $\mathrm{MeOH}$ or $4-\mathrm{OHT}$ for $48 \mathrm{~h}$. DNA was visualized by DAPI staining. (b) Quantitation of chromatin bridges. Experiments were performed as in a. At least 300 cells were scored for chromatin bridges and percentages of positive cells are shown. Three independent experiments were performed and mean \pm s.d. is shown. ${ }^{\star \star \star \star} P<0.0001$ (two-tailed unpaired $t$-test). (c) Quantitation of micronuclei-containing cells. Experiments were performed as in a. ${ }^{\star \star \star \star} P<0.0001$ (two-tailed unpaired $t$-test). (d) Formation of 53BP1 nuclear bodies. Sprth F/- MEFs were treated with $\mathrm{MeOH}$ or $4-\mathrm{OHT}$ for $48 \mathrm{~h}$. At least 300 cells were scored for 53BP1 nuclear bodies and percentages of nuclei with different number of 53BP1 nuclear bodies per nucleus are shown. (e) Chromosomal abnormalities in Sprtn KO cells. Sprtn ${ }^{\mathrm{F} /-} \mathrm{MEFs}$ were treated with $\mathrm{MeOH}$ or $4-\mathrm{OHT}$ for $48 \mathrm{~h}$. Twelve hours after completion of the treatments, mitotic spreads were prepared and examined by microscopy. Representative pictures of mitotic spreads are shown in the left panel. Arrows indicate some of the chromosome abnormalities. In the right panel, representative images of chromosome gaps in Sprtn KO MEFs are indicated by arrowheads. (f) Quantitation of abnormal chromosomes. Cells harbouring chromosomal abnormalities were scored in 50 mitotic spreads of Sprtn ${ }^{\mathrm{F} /-} \mathrm{MEFs}$ treated with $\mathrm{MeOH}$ or 4-OHT.

cells in $\operatorname{Sprtn}^{\mathrm{H} / \mathrm{H}}$ IAT were significantly smaller in size (Fig. 7d). Furthermore, IAT stained highly positive for senescenceassociated- $\beta$-galactosidase (SA- $\beta$-GAL) and showed increased levels of key senescence markers, including $\mathrm{p} 16^{\text {Ink4a }}, \mathrm{p} 19^{\text {Arf }}$ and PAI-1 (Fig. 7e,f). These data suggest that increased accumulation of cellular senescence in fat causes dysfunction and atrophy of this tissue. Lordokyphosis in progeroid mouse models is often associated with osteoporosis and/or muscle wasting ${ }^{24,26}$. However, neither disorder seemed to apply to $S p r t n^{\mathrm{H} / \mathrm{H}}$ mice as their bone mineral content and density (Supplementary Fig. 6a,b) and gastrocnemius, abdominal and paraspinal muscle fibre diameters (Supplementary Fig. 6c-e) were normal. Consistent with segmental progeria, $S p r t n^{\mathrm{H} / \mathrm{H}}$ mice showed impaired exercise ability as measured by the use of a treadmill: the duration of exercise, the distance travelled and the overall amount of work performed were all reduced at the age of 12 months (Fig. $7 \mathrm{~g}$ ). Taken together, these data suggest that the reduced expression of Sprtn leads to development of various progeroid phenotypes, including dwarfism, cataracts, lordokyphosis, fat tissue dysfunction and accumulation of senescent cells.

\section{Discussion}

In this study, we investigate the physiological roles of Spartan using a series of mice with graded reduction in Sprtn expression. Our data uncover a striking requirement of Spartan in cell survival and mouse development. Specifically, Sprtn KO causes early embryonic lethality in mice, while conditional KO in MEFs leads to incomplete DNA replication and cell death. In contrast, Sprtn hypomorphic mice are viable but develop premature ageing phenotypes accompanied by elevated levels of DNA damage and genome instability. Extending previous studies that implicated Spartan in TLS, we demonstrate that lesion bypass is impaired in Sprtn KO and hypomorphic cells when assayed with external DNA damage. Taken together, our data best fit a model whereby Spartan is essential for DNA replication under stress, which can 
a
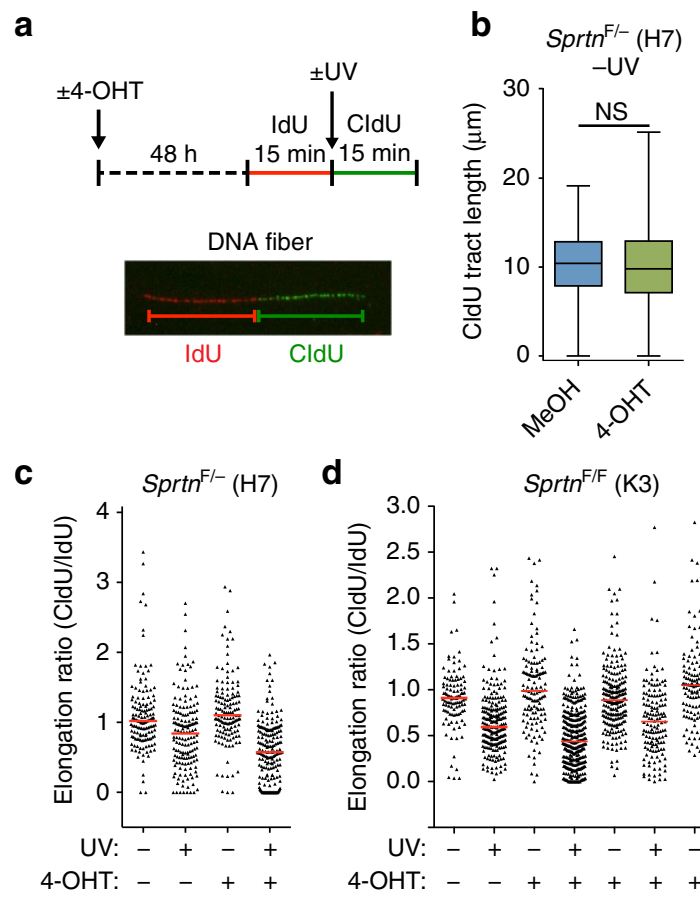

d
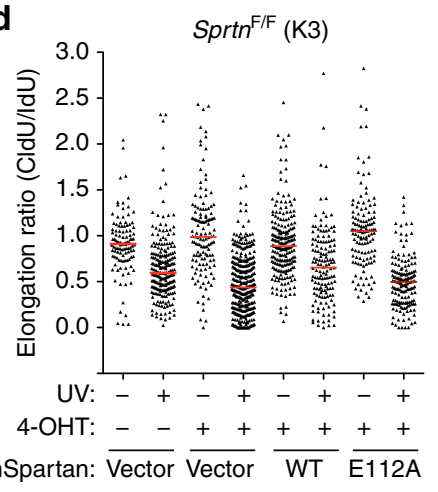

e
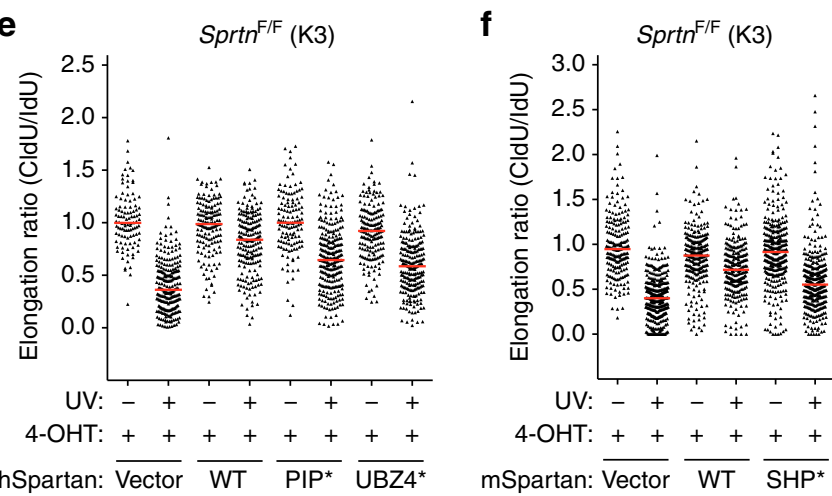

Figure 5 | Effects of Sprtn KO on DNA replication forks. (a) Schematic representation of DNA fiber assays. MEFs were treated with $\mathrm{MeOH}$ or 4-OHT for $48 \mathrm{~h}$ and sequentially labelled with IdU and CldU to mark ongoing replication. A picture of a representative replication track is shown. At least 100 fibres were scored for each sample in all of the DNA fiber experiments. (b) A box plot showing distribution of the lengths of CldU tracts in $\mathrm{Sprth}^{\mathrm{F} /}-\mathrm{MEFs}$ treated with $\mathrm{MeOH}$ or $4-\mathrm{OHT}$ for $48 \mathrm{~h}$. NS, not significant ( $P=0.829$, two-tailed unpaired $t$-test). (c) Effect of ultraviolet irradiation on replication forks. DNA fiber assays were performed with $\mathrm{Sprtn}^{\mathrm{F} /}-\mathrm{MEFs}$ with or without ultraviolet irradiation $\left(40 \mathrm{Jm}^{-2}\right)$ between IdU and CldU labelling. Distribution of replication forks at different CldU/ IdU ratios is shown. (d-f) Effect of ultraviolet irradiation on replication forks. Experiments were performed as in c using Sprtn ${ }^{\mathrm{F} / \mathrm{F}}$; Cre-ER ${ }^{T 2} \mathrm{MEFs}$ (K3) expressing wild-type human Spartan or the E112A mutant (d), wildtype human Spartan, the PIP* or the UBZ* mutant (e), and wild-type mouse Spartan or the $\mathrm{SHP}^{\star}$ mutant $(\mathbf{f})$. Horizontal red lines in $\mathbf{c}-\mathbf{f}$ indicate median values.

be imposed by DNA lesions or difficult-to-replicate sequences such as repetitive DNA elements. This model is also consistent with previous studies that have linked replication stress with agerelated phenotypes in mice ${ }^{4-6}$. In summary, our findings reveal the fundamental role of Spartan in the cell cycle and genome stability and support the link between deficiency in replication stress response and progeria.
To our knowledge, the current study is the first to demonstrate the requirement of Spartan in lesion bypass. This suggests that Spartan plays a more fundamental function than just suppressing damage-induced mutations. Our experiments using a various Spartan mutants provide mechanistic insight into the role of Spartan in lesion bypass. The results indicate that bypass of ultraviolet-induced lesions is dependent on the SprT domain of Spartan but only partially on the SHP, PIP and UBZ4 domains (Fig. 5d-f). The dependence on the SprT domain is consistent with our previous observation that suppression of ultravioletinduced mutagenesis by Spartan required an intact SprT domain ${ }^{15}$. On the other hand, the partial requirement of the PIP and UBZ4 domains indicates that recruitment of Spartan to ubiquitinated PCNA is important, but not absolutely necessary for Spartan's function in lesion bypass. This is consistent with the report that PCNA ubiquitination is important but not absolutely required for $\mathrm{TLS}^{27}$. Although not absolutely required, the SHP box of Spartan clearly has an important role in lesion bypass. Previous reports suggested a model in which the Spartan-p97 interaction facilitates p97-mediated removal or degradation of Pol $\eta$ from DNA damage sites. Consistent with this model, Sprtn $^{-1}$ - MEFs showed prolonged retention of ultraviolet-induced Pol $\eta$ foci (Supplementary Fig. 3d). Our findings that both the SprT domain and the SHP box are involved in lesion bypass raise an intriguing possibility that p97 and the SprT domain of Spartan cooperate in polymerase switching at the sites of TLS.

Although it is not clear why Sprtn KO cells die, it is tempting to speculate that failure to execute TLS is a major contributing factor given that the catalytic subunit of the TLS polymerase Pol $\zeta$ has been shown to be essential in mice ${ }^{28-33}$. Consistently, our previous study implicated Spartan in regulation of Pol $\zeta^{15}$. Therefore, Spartan might be required for efficient TLS in response to stalled replication at endogenous DNA damage sites, thereby allowing cells to complete $S$ phase. In addition, given that TLS polymerases are important for efficient replication and stability of difficult-toreplicate sequences ${ }^{34-37}$, it is possible that Spartan-deficient cells exhibit cell cycle defects and genome instability due to replication failure at the sites of inherent replication stress such as difficult-toreplicate regions. Alternatively, given the previous observation that Spartan interacts with the DNA polymerase $\delta$ subunit $^{10,15}$, it is possible that Spartan has a more general role in DNA replication unrelated to the TLS pathway. In this case, Spartan might be dispensable for replication of the majority of the genome, with only certain regions requiring Spartan function. Our experiments found that distinguishing these two possibilities might be challenging, because PIP and UBZ4, two TLS-linked domains of Spartan, were not only dispensable for cell viability (Supplementary Fig. 2d), but also not completely required for the function of Spartan in lesion bypass (Fig. 5e). In contrast, we found that the SprT is necessary for both lesion bypass and cell viability (Fig. 5d). Therefore, functional studies of the putative zinc metalloprotease domain in TLS or other processes will clarify the cause of incomplete DNA replication and cell death following Sprtn KO.

We find that Spartan deficiency leads to both structural and numerical chromosome instabilities, both of which have been associated with cancer predisposition. $\operatorname{Sprtn}^{\mathrm{H} / \mathrm{H}}$ mice sacrificed at 1 year of age were thoroughly screened for the presence of tumours, but none were detected. On the other hand, with $100 \%$ penetrance, these mice presented multiple age-related and progeroid phenotypes, suggesting that the genomic stress resulting from Spartan insufficiency predominantly engages signalling pathways that have been associated with cell fate decisions that negatively impact tissue homeostasis and repair, such as the p53 and the p16 $6^{\text {Ink4a }}$ tumour suppressor pathways ${ }^{38}$. Consistent with this, we observed a profound accumulation of senescent cells in fat tissue of Spartan-insufficient mice, as well as 


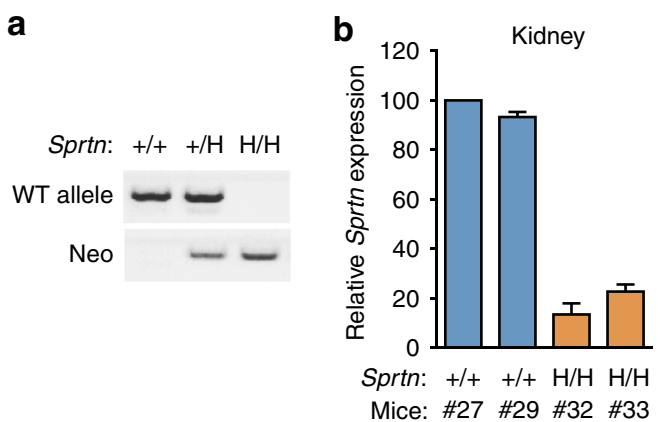

d

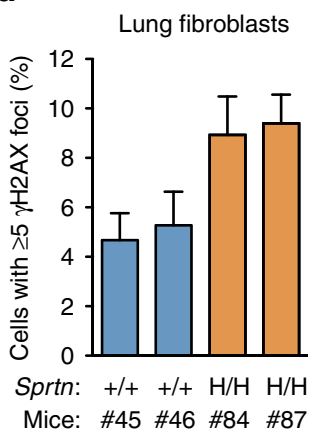

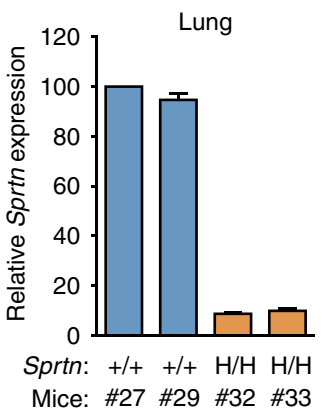

e

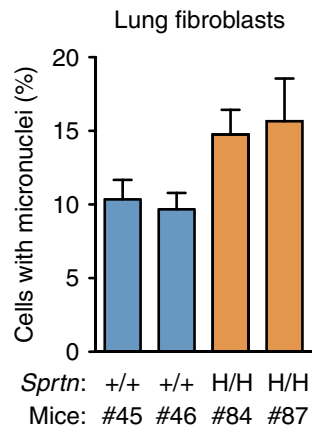

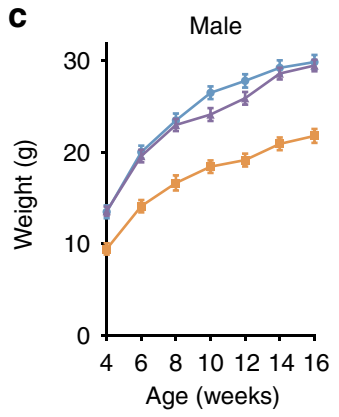
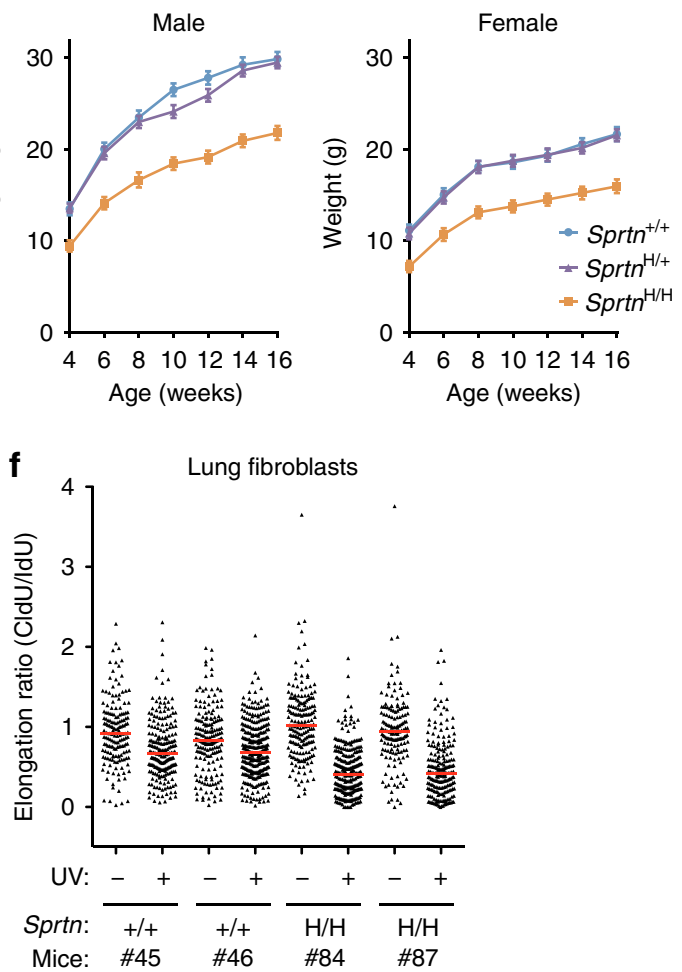

Figure 6 | Characterization of Sprtn hypomorphic cells and mice. (a) PCR-based genotyping of Sprtn ${ }^{+/+}$, Sprtn ${ }^{+/ H}$ and Sprtn ${ }^{H / H}$ mice at weaning. (b) Quantitative PCR analyses of Sprtn mRNA levels in Sprtn ${ }^{+/+}$and Sprtn ${ }^{\mathrm{H} / \mathrm{H}}$ mice. Sprtn mRNA levels in the kidneys (left) and lungs (right) of two mice per genotype were measured three times by quantitative reverse transcription PCR and mean \pm s.d. is shown. Values were normalized to Gapdh and shown relative to Sprtn ${ }^{+/+}$mouse \#27. (c) Growth curves of Sprtn ${ }^{+/+}$, Sprtn ${ }^{+/ H}$ and Sprtn ${ }^{\mathrm{H} / \mathrm{H}}$ mice $(n=5$, mean \pm s.d.) of 4-16 weeks. (d,e) Quantitation of cells containing five or more $\gamma \mathrm{H} 2 \mathrm{AX}$ foci $(\mathbf{d})$ and micronuclei $(\mathbf{e})$ in the indicated Sprtn ${ }^{+/+}$and $\mathrm{Sprtn} \mathrm{H}^{\mathrm{H} / \mathrm{H}}$ primary lung fibroblasts. At least 300 cells were scored in each experiment and percentages of positive cells are shown. Values are mean \pm s.d. of three independent experiments. For d,e, statistical significance is $P<0.001$ ( $\mathrm{H} / \mathrm{H}$ group versus $+/+$ group), two-tailed unpaired $t$-test. (f) Effect of ultraviolet irradiation on replication forks. DNA fiber assays were performed with Sprtn ${ }^{+/+}$and Sprtn ${ }^{\mathrm{H} / \mathrm{H}}$ primary lung fibroblasts with or without ultraviolet irradiation $\left(40 \mathrm{~J} \mathrm{~m}^{-2}\right.$ ) between IdU and CldU labelling. Distribution of replication forks at different CldU/IdU ratios is shown. A horizontal red line indicates median value.

Table 3 | Karyotypes of primary lung fibroblasts.

\begin{tabular}{|c|c|c|c|c|c|c|c|c|c|}
\hline \multirow[t]{2}{*}{ Lung fibroblast genotype $(n)$} & \multirow[t]{2}{*}{ Mitotic cells inspected } & \multirow[t]{2}{*}{$\%$ Aneuploid figures } & \multicolumn{7}{|c|}{ Karyotypes with the indicated chromosome number } \\
\hline & & & 37 & 38 & 39 & 40 & 41 & 42 & 43 \\
\hline Sprtn+/+(2) & 50 & 12 & 0 & 3 & 1 & 44 & 1 & 1 & 0 \\
\hline $\operatorname{Sprtn}^{\mathrm{H} / \mathrm{H}}(2)$ & 50 & 36 & 1 & 5 & 2 & 32 & 6 & 2 & 2 \\
\hline
\end{tabular}

Karyotyping was performed with lung fibroblasts isolated from two mice per genotype (\#45 and \#46 for Sprtn ${ }^{+/+}, \# 84$ and $\# 87$ for Sprtn ${ }^{\mathrm{H} / \mathrm{H}}$ ) at passage 5 . Twenty-five mitotic figures were inspected for each sample.

increased levels of $\mathrm{p} 16^{\mathrm{Ink} 4 \mathrm{a}}$. Several genome maintenance syndromes have exclusively been associated with progeria, including Cockayne syndrome, trichothiodystrophy, RothmundThomson and dyskeratosis congenital, while others, including Fanconi anaemia, xeroderma pigmentosum, ataxia telangiectasia, Nijmegen breakage syndrome, Bloom syndrome and Werner syndrome, cause both cancer and progeroid phenotypes ${ }^{39}$. Our data suggest that Spartan insufficiency primarily causes progeria; however, it will be important to screen a larger cohort of Sprtn $\mathrm{H} / \mathrm{H}$ mice for tumour formation in future studies. While this manuscript was under review, Lessel et al. ${ }^{40}$ reported biallelic germline mutations in Sprtn in human patients with a new segmental progeroid syndrome. Accelerated ageing in Sprtn hypomorphic mice in our study is consistent with the progeria in the human patients, and our study provides a firm link between Spartan insufficiency and premature ageing.
In conclusion, the current study provides the evidence that Spartan is essential for the normal cell cycle and cell viability. Our data strongly suggest that Spartan deficiency causes cell cycle defects through accumulation of incompletely replicated genomic regions. Further studies on the potential enzyme activity of the SprT domain will reveal the full function of Spartan and provide insight into the mechanism by which insufficiency of Spartan leads to genome instability and progeria.

\section{Methods}

Generation of Sprtn-targeted mice. The Sprtn-targeting vector was constructed in modified pNTKV1901-frt/loxP 22 with a new MfeI site for left homology arm cloning. Mouse Sprtn genomic sequences were amplified by PCR from a BAC clone (RPCI-23 bMQ384-H14) using following primers. Left homology arm forward, $5^{\prime}$-GCATCAGATATCTAAAGGCTTCCTTCCACATGCTAC- $3^{\prime}$; left homology arm reverse, 5'-GCATCACAATTGATCTCCGAGTTCCAGGCCA GC-3'; exon 2 forward, $5^{\prime}$-GCATCAAAGCTTGAATTCCCTCCTGCATCTGC 
a

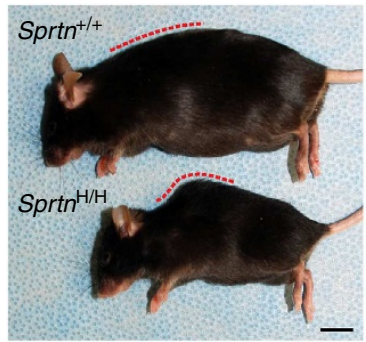

c

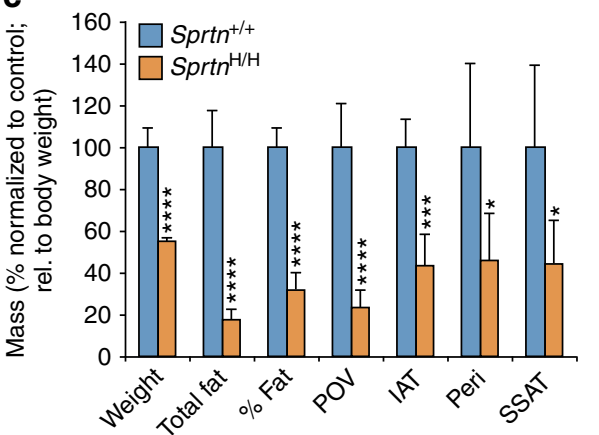

b

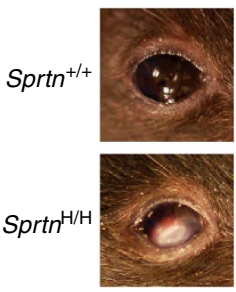

d e

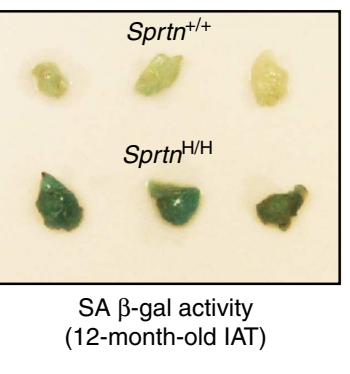

f

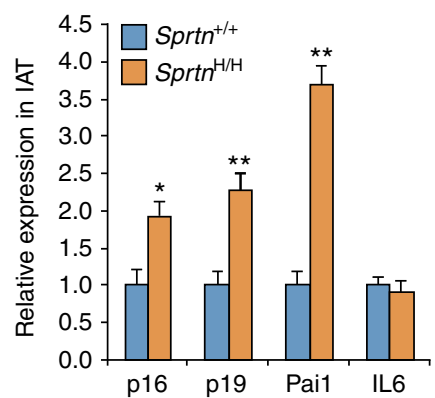

g

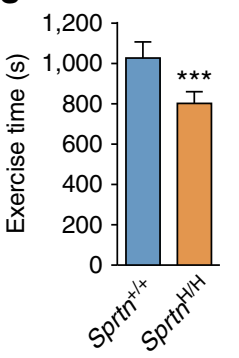

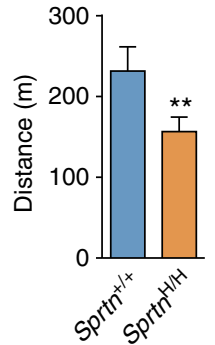

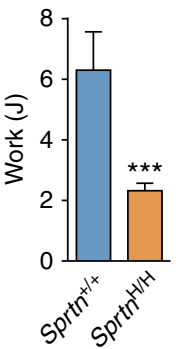

Figure 7 | Premature ageing phenotypes in Sprtn $\mathbf{H} / \mathbf{H}$ mice. (a) Representative images of 12-month-old Sprtn $+/+$ and Sprtn $\mathrm{H} / \mathrm{H}$ female mice. Note lordokyphosis in Sprtn ${ }^{\mathrm{H} / \mathrm{H}}$ indicated by the dotted red line. Scale bar, $1 \mathrm{~cm}$. (b) Representative images of the eyes of Sprtn $+/+$ and Sprtn ${ }^{\mathrm{H} / \mathrm{H}}$ female mice. Note a cataract in Sprtn ${ }^{\mathrm{H} / \mathrm{H}}$. (c) Body weight, fat mass, body fat percentage and adipose depot weights of 12 -month-old Sprtn ${ }^{+/+}$and Sprtn ${ }^{\mathrm{H} / \mathrm{H}}$ female mice $\left(n=5\right.$, mean \pm s.d.). Values are normalized to the average of the Sprtn ${ }^{+/+}$mice. Because of the smaller body size of the Sprtn ${ }^{\mathrm{H} / \mathrm{H}}$ mice, adipose depot measurements were first calculated relative to body weight. (d) Fat cell diameter measurements $(n=5$, mean \pm s.d.). (e) IAT of 12-month-old mice stained for SA- $\beta$-gal activity. (f) Relative expression of senescence markers in 12 -month-old IAT ( $n=5$, mean \pm s.d.). Values were normalized to Gapdh and are relative to Sprtn $+/+$ IAT. (g) Treadmill exercise ability of 12 -month-old Sprtn ${ }^{+/+}$and Sprtn ${ }^{\mathrm{H} / \mathrm{H}}$ female mice. Exercise time, distance travelled and workload performed are shown $\left(n=5\right.$, mean \pm s.d.). For all panels, statistical significance is as follows: ${ }^{\star} P<0.05,{ }^{\star \star} P<0.01,{ }^{\star \star \star} P<0.001,{ }^{\star \star \star \star} P<0.0001$ (two-tailed unpaired $t$-test).

CTTCCACG-3'; exon 2 reverse, 5'-GCATCAGGTACCGTATGGGCTGCTAT CAAGAACC-3'; right homology arm forward, $5^{\prime}$-GCATCACCGCGG AAGCTTTGGCTTCAACCACAAGATCCTC-3'; right homology arm reverse, 5'-GCATCAGTCGACTCAGGGACTCCAGATAAGACTAC- $3^{\prime}$. After electroporation into $129 \mathrm{~Sv} / \mathrm{E}$ mouse embryonic stem cells and selection under G418, correctly targeted clones were injected into blastocysts and resulting chimeric mice were used to generate Sprtn ${ }^{\mathrm{Neo} /+}$ mice. Sprtn ${ }^{+1-}$ mice were generated by crossing Sprtn $\mathrm{NeO} /+$ mice and Cre-transgenic mice. A conditional KO allele (F allele), in which exon 2 is floxed, was created by crossing Sprtn ${ }^{\mathrm{Neo} /+}$ mice with FLP-transgenic mice. Sprtn $\mathrm{F}^{\mathrm{F}}+$ mice were crossed with Cre-ER $R^{T 2}$-transgenic mice (B6.129-Gt(ROSA)26Sor ${ }^{t m 1}\left(\right.$ cre/ERT2)Tyj/J $^{41}$ to generate Sprtn ${ }^{\mathrm{F} /+} ; \mathrm{Cre}-E R^{T 2}$ mice. Sprtn ${ }^{\mathrm{H} / \mathrm{H}}$ mice were generated by intercrossing Sprtn ${ }^{\mathrm{Neo} /+}$ mice. All mice were maintained on a mixed 129Sv/E $\times$ C57BL/6 genetic background. Genotyping was performed by PCR analyses of tail DNA using three primers: wild-type-specific forward ( $5^{\prime}$-GTGCTGGGATCTGCACCTAT-3'), KO-specific forward (5'-

CCATCAGGGACGTTTTCTTG- $\left.3^{\prime}\right)$ and common reverse ( $5^{\prime}$-TGCACAGCTGT AAACCCTTG- $\left.3^{\prime}\right)$. To detect the Neo $(\mathrm{H})$ allele, Neo forward $\left(5^{\prime}\right.$-TCCCAAGT GCTGGGATTAAG- $3^{\prime}$ ) and Neo reverse (5'-TCGCCTTCTTGACGAGTTCT- $3^{\prime}$ ) primers were used. PCR conditions were 35 cycles of $94^{\circ} \mathrm{C}$ for $30 \mathrm{~s}, 60^{\circ} \mathrm{C}$ for $30 \mathrm{~s}$ and $72{ }^{\circ} \mathrm{C}$ for $1 \mathrm{~min}$. The PCR products are $425 \mathrm{bp}$ (base pair) for the wild-type allele, $278 \mathrm{bp}$ for the KO allele, $527 \mathrm{bp}$ for the floxed allele and $442 \mathrm{bp}$ for the Neo $(\mathrm{H})$ allele. All of the animal procedures were approved by Mayo Clinic Institutional Animal Care and Use Committee.
In vitro culture of mouse blastocysts. All blastocysts were generated by natural mating of 2- to 3-month old Sprtn ${ }^{+/-}$male and Sprtn ${ }^{+/-}$female mice. The morning of the day on which a vaginal plug was detected was designated as day E0.5. Blastocysts were collected on E3.5 by flushing the uteri with M2 medium (Sigma, \#M7167) and cultured on 35-mm glass-bottom dishes (FluoroDish FD35, World Precision Instruments) in G-1 ${ }^{\text {TM }}$ v5 PLUS medium (Vitrolife, \#10128) under paraffin oil (Vitrolife, \#10029). Each blastocyst was photographed daily using a Zeiss Axio Observer $\mathrm{Z} 1$ system with $\mathrm{CO}_{2}$ Module $\mathrm{S}\left(5 \% \mathrm{CO}_{2}\right)$, TempModule S $\left(37^{\circ} \mathrm{C}\right)$, Heating Unit XL S $\left(37^{\circ} \mathrm{C}\right)$, A-Pln $10 \mathrm{X} / 0.25 \mathrm{Ph} 1$ objective, AxioCam MRm camera and AxioVision 4.8 software. Images were exported as jpeg files, subsequently cropped and adjusted for brightness and contrast. At day 6 , the blastocyst-outgrowing cells or the undeveloped blastocysts were collected using a microneedle and suspended in $50 \mu \mathrm{l}$ lysis buffer $(60 \mathrm{mM}$ Tris- $\mathrm{HCl}, \mathrm{pH} 9.0,15 \mathrm{mM}$ $\left[\mathrm{NH}_{4}\right]_{2} \mathrm{SO}_{4}, 2 \mathrm{mM} \mathrm{MgCl} 2,0.5 \%$ Tween-20 (v/v) and $250 \mu \mathrm{g} \mathrm{ml}{ }^{-1}$ proteinase $\left.\mathrm{K}\right)^{42}$. For PCR-based genotyping, 3-10 $\mu \mathrm{l}$ from each sample was used in $25 \mu \mathrm{l}$ reactions. Genotyping was performed in duplicate and was successful for all of the blastocysts collected.

Analysis of ageing-associated phenotypes. Body composition was determined using an EchoMRI-100TM QNMR instrument (Echo Medical Systems, Houston, Texas) in 12-month-old female mice. Total body fat and lean mass were measured. Total body fat percentage is equal to fat mass divided by body mass. Bone mineral 
density and bone mineral content were determined with dual-energy X-ray absorptiometry scanning using a Lunar PIXImus densitometer. Forelimb strength (N) was determined using a grip strength meter from Columbus Instruments. Three consecutive days of acclimation occurred before testing. Treadmill exercise tests were performed as previously described ${ }^{43}$. Briefly, the mice were put on the treadmill that was programmed at $5 \mathrm{~m} \mathrm{~min}^{-1}$ of speed for $2 \mathrm{~min}$, which after $2 \mathrm{~min}$ was increased to $8 \mathrm{~m} \mathrm{~min}^{-1}$. The speed of the treadmill was then increased every $2 \mathrm{~min}$ at the rate of $2 \mathrm{~m} \mathrm{~min}^{-1}$. The exercise time and distance travelled were determined at the point when the mice were unable to move along the treadmill. Work $(\mathrm{J})$ done was determined by: mass $(\mathrm{kg}) \times g\left(9.8 \mathrm{~m} \mathrm{~s}^{-2}\right) \times$ distance $(\mathrm{m}) \times \sin (\theta)$ (where, $\theta=5^{\circ}$ ). Individual adipose depots and gastrocnemius muscle were isolated and weighed on sacrifice. All weights were calculated relative to total body weight. Adipose depot measurements were normalized to the average of the five control animals. Formalin-fixed, paraffin-embedded inguinal adipose (IAT) cell and skeletal muscle fibre diameter measurements were performed using a calibrated computer program (Olympus Microsuite Five) ${ }^{43}$. Fifty fibres per sample were measured. To determine SA- $\beta$-gal activity, IAT was fixed with fixative solution containing $2 \%$ formaldehyde and $0.2 \%$ glutaraldehyde for $12 \mathrm{~min}$ at room temperature, followed by $12 \mathrm{~h}$ incubation with $\beta$-galactosidase staining solution containing $1 \mathrm{mg} \mathrm{ml}^{-1} \mathrm{X}$-gal at $37^{\circ} \mathrm{C}$.

Plasmids and viral infection. Complementary DNA fragments encoding wildtype, the E112A mutant, the YFAA mutant (PIP*) and the D473A mutant (UBZ4*) of human Spartan ${ }^{11,15}$ were subcloned into a retrovirus vector pMSCV-puro. Wildtype mouse Spartan and Spartan ${ }^{\text {SHP }^{*}}$ (harbouring F254A and L261A mutations) were cloned into pMSCV-puro with an amino-terminal 3xFlag tag. Full-length Pol $\eta$ cDNA was subcloned from pEGFP-C-pol $\eta$ (a gift from Chikahide Masutani and Fumio Hanaoka) into a lentiviral expression vector pLVX6-IRES-Neo (N-terminal EGFP tag). Retroviruses and lentiviruses were packaged by cotransfecting viral and packaging plasmids in a human embryonic kidney cell line 293T (American Type Culture Collection, CRL-11268). Cells were infected with viral vectors in the presence of $2 \mu \mathrm{g} \mathrm{ml}^{-1}$ polybrene and selected with $3 \mu \mathrm{g} \mathrm{ml}^{-1}$ puromycin or $400 \mu \mathrm{g} \mathrm{ml}^{-1} \mathrm{G} 418$.

Cell culture. MEFs were cultured in Dulbecco's modified Eagle Medium (DMEM) supplemented with $10 \%$ fetal bovine serum (FBS). Primary Sprtn ${ }^{\mathrm{H} /}-\mathrm{MEFs}$ were isolated from E13.5 embryos obtained by crossing Sprtn ${ }^{+}-{ }_{-}$and $S_{p r t n} \mathrm{H} /+$ mice. The H-line MEFs (H2, H3, H5 and H7) were obtained from E13.5 embryos produced by crossing Sprtn ${ }^{+1-}$ and $S p r t n^{\mathrm{F} /+}$ mice and immortalized by serial passage. For Cre-ER ${ }^{T 2}$ expression in the $\mathrm{H}$-line MEFs, cells were infected with retroviral vectors and selected with $3 \mu \mathrm{g} \mathrm{ml}^{-1}$ puromycin. The K-line MEFs (K3) were isolated from E13.5 embryos produced by crossing Sprtn ${ }^{\mathrm{F} /+} ; \mathrm{Cre}-E R^{T 2}$ and Sprtn $^{\mathrm{F} /}+$ mice and immortalized by retroviral expression of SV40 T-antigen ${ }^{44}$. To induce conversion of the floxed allele to the KO allele in MEFs, cells were treated with methanol $(\mathrm{MeOH})$ or $2 \mu \mathrm{M} 4-\mathrm{OHT}$ dissolved in $\mathrm{MeOH}$ for 2 days. For cell proliferation assays, $1.5 \times 10^{5}$ cells were seeded in $10 \mathrm{~cm}$ dishes and cell numbers were recorded every $24 \mathrm{~h}$ for 4 days.

Sprtn $+1+$ and Sprtn ${ }^{\mathrm{H} / \mathrm{H}}$ primary lung fibroblasts were isolated from lung tissues of Sprtn ${ }^{+1}+$ and $S p r t n^{\mathrm{H} / \mathrm{H}}$ male mice, respectively. Briefly, the lungs were chopped into small pieces and allowed to sit for few minutes in $100 \mathrm{~mm}$ dishes. Culture medium (DMEM supplemented with 10\% FBS, non-essential amino acids, sodium pyruvate and 2-mercaptoethanol) was added to the dishes and cells were cultured for 4 days. All experiments were performed within three to six passages.

Prostate epithelial cells were isolated as described previously with modifications ${ }^{45}$. Briefly, prostate tissues were chopped into small pieces, minced in $1 \mathrm{ml}$ of phosphate-buffered saline (PBS) containing $0.5 \%$ BSA and $2 \mathrm{mM}$ EDTA using gentleMACS Dissociator (Miltenyi Biotec) and incubated with $7 \mathrm{mg} \mathrm{ml}^{-1}$ Liberase blendzyme 3 (Roche) at $37^{\circ} \mathrm{C}$ for $30 \mathrm{~min}$. After subsequent dissociation with gentleMACS Dissociator and centrifugation (1,000 r.p.m., 15 s), cell suspensions were collected and cleared from undigested tissues using a cell strainer. Prostate epithelial cells were then co-cultured with irradiated $(3,000 \mathrm{rad}) \mathrm{J} 2$ fibroblast feeder cells ${ }^{46}$ in DMEM/F12 (3:1) supplemented with 10\% FBS, $25 \mathrm{ng} \mathrm{ml}^{-1}$ hydrocortisone, $0.125 \mathrm{ng} \mathrm{ml}^{-1}$ EGF, $5 \mu \mathrm{g} \mathrm{ml}^{-1}$ insulin, $0.1 \mathrm{nM}$ cholera toxin and $250 \mathrm{ng} \mathrm{ml}^{-1}$ Fungizone. Experiments were performed using epithelial cells at passage 4 after separation from feeder cells.

Flow cytometry. For analyses of DNA content, cells were harvested and fixed with $70 \%$ ethanol at $-20^{\circ} \mathrm{C}$ overnight. Fixed cells were stained with propidium iodide (PI) solution $\left(50 \mu \mathrm{g} \mathrm{ml}^{-1} \mathrm{PI}, 10 \mu \mathrm{g} \mathrm{ml}^{-1}\right.$ RNase A, $0.05 \%$ Nonidet P-40 (NP-40)) for at least $30 \mathrm{~min}$ and analysed by FACS Canto II (BD Biosciences). Percentages of the cell cycle phases were estimated using ModFit LT (Verity Software House). For detection of apoptosis, adherent and floating cells were harvested and stained with Annexin V-APC (BD Biosciences) for $15 \mathrm{~min}$ at room temperature. Cells were then stained with $100 \mu \mathrm{g} \mathrm{ml}^{-1}$ PI and analysed by the flow cytometer.

To analyze S-phase progression, cells were pulse labelled with $10 \mu \mathrm{M}$ BrdU for $30 \mathrm{~min}$ and chased in BrdU-free media every $2 \mathrm{~h}$. Cells were harvested and fixed in $70 \%$ ethanol at $-20^{\circ} \mathrm{C}$ overnight. DNA was denatured by suspending cells in $2 \mathrm{~N}$ $\mathrm{HCl}$ with $0.5 \%$ Triton X-100 for $30 \mathrm{~min}$ at room temperature. After neutralization with $0.1 \mathrm{M}$ sodium borate ( $\mathrm{pH} 8.5$ ), cells were labelled with $1 \mu \mathrm{g}$ of fluorescein isothiocyanate-conjugated anti-BrdU antibody (Roche, \#11202693001) for $30 \mathrm{~min}$ at room temperature. Finally, cells were stained with PI solution $\left(50 \mu \mathrm{g} \mathrm{ml}^{-1} \mathrm{PI}\right.$, $10 \mu \mathrm{g} \mathrm{ml}^{-1}$ RNase A, $0.05 \% \mathrm{NP}-40$ ) for at least $30 \mathrm{~min}$ and analysed by flow cytometry. For phospho-histone $\mathrm{H} 3$ (Ser10), cells were incubated with $40 \mathrm{ng} \mathrm{ml}^{-1}$ nocodazole (Sigma) for $4 \mathrm{~h}$, harvested and fixed with $70 \%$ ethanol at $-20^{\circ} \mathrm{C}$ overnight. Cells were washed once with PBS containing $1 \%$ BSA (1\% BSA/PBS) and permeabilized with $1 \%$ BSA/PBS containing $0.25 \%$ Triton X-100 for 5 min at $4{ }^{\circ} \mathrm{C}$. After washing with $1 \% \mathrm{BSA} / \mathrm{PBS}$, cells were resuspended in $1 \mu \mathrm{g}$ of antiphospho-H3 (Millipore, \#06-570) in 1\% BSA/PBS containing $10 \%$ normal goat serum and incubated overnight at $4{ }^{\circ} \mathrm{C}$. Cells were washed once with $1 \%$ BSA/PBS and incubated with $7 \mu \mathrm{g}$ of Alexa Fluor 488-labelled goat anti-rabbit IgG (Invitrogen, \#A11034) in 1\% BSA/PBS containing 10\% normal goat serum for $1 \mathrm{~h}$ at $4{ }^{\circ} \mathrm{C}$. After washing with $1 \% \mathrm{BSA} / \mathrm{PBS}$, cells were incubated in PI solution for at least $30 \mathrm{~min}$ and analysed by flow cytometry.

Cytogenetics. Mitotic cells were enriched by colcemid treatment for $2 \mathrm{~h}$ and harvested by tapping plates. Cells were then swollen in hypotonic buffer for $25 \mathrm{~min}$, fixed and dropped on glass slides. Slides were baked at $90^{\circ} \mathrm{C}$ for $90 \mathrm{~min}$ and stained with Leishman's stain solution for 1-3 min. After a brief rinse with running water, slides were dried at room temperature and analysed using a bright-field microscope. A metaphase spread was considered positive for breakage if any minor anomalies, major anomalies or radial configurations were observed.

Chromatin fractionation and western blot. Cells were lysed in NETN lysis buffer (20 mM Tris-HCl, pH 8.0, $100 \mathrm{mM} \mathrm{NaCl}, 0.5 \%$ NP-40, 1 mM EDTA, $0.5 \mathrm{mM} \mathrm{NaF}$, $1 \mathrm{mM} \beta$-glycerophosphate) supplemented with protease inhibitor mix (Sigma) followed by sonication. Chromatin-enriched fractionations were isolated by a previously described method ${ }^{47}$ with modifications. Briefly, cells were incubated in buffer A (10 mM Pipes (pH 6.8), $100 \mathrm{mM} \mathrm{NaCl}, 3 \mathrm{mM} \mathrm{MgCl}_{2}, 300 \mathrm{mM}$ sucrose, $1 \mathrm{mM}$ EGTA, $0.2 \%$ Triton X-100, protease inhibitor mix (Sigma)) at $4{ }^{\circ} \mathrm{C}$ with rotation for $5 \mathrm{~min}$. After centrifugation, pellets were washed again with buffer A and then incubated on ice for $30 \mathrm{~min}$ in buffer B $(50 \mathrm{mM}$ Tris- $\mathrm{HCl}(\mathrm{pH} 7.5)$, $150 \mathrm{mM} \mathrm{NaCl}, 0.1 \%$ SDS) containing $500 \mathrm{U} \mathrm{ml}^{-1}$ Benzonase (Merck Millipore) followed by sonication. Supernatants containing solubilized chromatin proteins were recovered after centrifugation (14,000 r.p.m., $10 \mathrm{~min}$ ). Thirty micrograms of proteins was separated by SDS-PAGE, transferred to nitrocellulose membranes and probed with antibodies. Antibodies against phospho-Chk1 (Ser345) (\#2348, 1:1,000) and histone H3 (\#9715, 1:5,000) were purchased from Cell Signaling Technology. Anti-Chk1 (\#sc-8408, 1:1,000), anti-PCNA (\#sc-56, 1:2,000) and antiMCM7 (\#sc-9966, 1:1,000) antibodies were from Santa Cruz Biotechnology. AntiChk2 antibodies were obtained from BD Biosciences (\#611570, 1:1,000). Anti-Flag (\#F1804, 1:2,000) and anti- $\beta$-actin (\#A5316, 1:5,000) antibodies were purchased from Sigma. Mouse anti-human Spartan antibodies were reported previously ${ }^{11}$

Immunofluorescence and microscopy. Cells were fixed with $4 \%$ paraformaldehyde for $10 \mathrm{~min}$ at room temperature and permeabilized for $10 \mathrm{~min}$ with $0.2 \%$ Triton X-100. Cells were blocked for $1 \mathrm{~h}$ in PBS containing 3\% BSA (Rad51), 1\% normal goat serum (53BP1, $\gamma \mathrm{H} 2 \mathrm{AX}$ ) or $3 \%$ normal goat serum $(\gamma \mathrm{H} 2 \mathrm{AX}$ for primary lung fibroblasts) and incubated with primary antibodies diluted in the respective blocking solution for $1 \mathrm{~h}$ at room temperature. Antibodies used were: rabbit anti-Rad51 (Calbiochem, \#PC130, 1:100), rabbit anti-53BP1 (a gift from Zhenkun Lou, 1:500) and rabbit anti- $\gamma$ H2AX (Cell Signaling Technology, \#2577, 1:500). After washing with PBS, cells were stained with secondary antibodies (Invitrogen, Alexa fluor 488 goat anti-rabbit IgG, \#A11034, 1:2,000) diluted in the blocking solution for $30 \mathrm{~min}$ at room temperature. Cells were washed with PBS, stained with DAPI $\left(0.1 \mu \mathrm{g} \mathrm{ml}^{-1}\right.$, Sigma) for $5 \mathrm{~min}$ and mounted with ProLong Gold (Invitrogen). For analyses of micronuclei and chromatin bridges, cells were fixed as above or with methanol:acetone $(3: 1)$ for $10 \mathrm{~min}$ at $-20^{\circ} \mathrm{C}$ and permeabilized for $10 \mathrm{~min}$ with $0.2 \%$ Triton X-100 at room temperature, stained with DAPI $\left(0.1 \mathrm{~g} \mathrm{ml}^{-1}\right.$, Sigma) for $5 \mathrm{~min}$ and mounted with ProLong Gold (Invitrogen). Slides were viewed and photographed on a Zeiss fluorescent microscope with a $\times 100$ objective.

DNA fiber assays. Cells were labelled with $25 \mu \mathrm{M}$ IdU (Sigma) for $15 \mathrm{~min}$, washed twice with pre-warmed PBS and labelled with $200 \mu \mathrm{M}$ CldU (Sigma) for $15 \mathrm{~min}$. To measure fork progression at DNA lesions, cells were irradiated with $40 \mathrm{~J} \mathrm{~m}^{-2}$ ultraviolet in $5 \mathrm{ml}$ media containing $1 \%$ FBS in $100 \mathrm{~mm}$ dish between IdU and CldU labelling. Labelled cells were harvested and mixed with unlabelled cells at $1: 40$ and concentrations were adjusted to $3-5 \times 10^{5} \mathrm{ml}^{-1}$ in PBS. Five microlitres of cell suspension was dropped on a glass slide and cells were lysed by adding $15 \mu \mathrm{l}$ spreading buffer (200 mM Tris-HCl, pH 7.4, $50 \mathrm{mM}$ EDTA, 0.5\% SDS). After $8 \mathrm{~min}$ incubation at room temperature, DNA was spread by tilting glass slides and fixed with methanol/acetic acid (3:1) for $10 \mathrm{~min}$. Slides were incubated with $2.5 \mathrm{M}$ $\mathrm{HCl}$ for $1 \mathrm{~h}$, neutralized by rinsing twice with $0.1 \mathrm{M}$ sodium borate $(\mathrm{pH} 8.5)$, washed with PBS, blocked with PBS containing 5\% goat serum for $1 \mathrm{~h}$ and incubated with anti-IdU antibodies (BD Biosciences, \#347580, 1:100 in PBS containing $5 \%$ goat serum) overnight at $4{ }^{\circ} \mathrm{C}$. After washing with low-salt TBST $(36 \mathrm{mM}$ Tris- $\mathrm{HCl}, \mathrm{pH} 8.0,50 \mathrm{mM} \mathrm{NaCl}, 0.5 \%$ Tween-20) for $20 \mathrm{~min}$ and then twice with PBST (PBS containing 0.2\% Tween-20), slides were incubated with anti-CldU 
antibodies (Abcam, \#ab6326, 1:1,000 in PBS containing 5\% goat serum) overnight at $4{ }^{\circ} \mathrm{C}$. Slides were washed three times with PBST and incubated with secondary antibodies (Invitrogen, Alexa fluor 594 anti-mouse IgG, \#A11032, Alexa fluor 488 anti-rat IgG, \#A11006, 1:2,000 in PBS containing 5\% goat serum) for $30 \mathrm{~min}$ at $37^{\circ} \mathrm{C}$. After washing with PBST, slides were mounted with ProLong Gold (Invitrogen). Slides were viewed and photographed on a Zeiss fluorescent microscope with a $\times 100$ objective. The lengths of IdU and CldU tracts were measured using the ImageJ software.

Quantitative reverse transcription-PCR. Total RNA was isolated from the kidneys and lungs of Sprtn $+1+$ and $S p r t n^{\mathrm{H} / \mathrm{H}}$ mice using TRIzol (Invitrogen) and from MEFs and IAT using RNeasy Kit (Qiagen). cDNAs were generated using oligo(dT) primers and SuperScript III (Invitrogen). Quantitative PCR was performed in triplicate for each sample on CFX96 (Bio-Rad) using iTaq Universal SYBR Green Supermix (Bio-Rad) or on ABI PRISM 7900 Sequence Detection System (Applied Biosystems) using SYBR green PCR Master Mix (Applied Biosystems). To quantify the wild-type Sprtn transcripts, primers were designed at the junction of exon 2 and exon 3 (forward primer: $5^{\prime}$-GGACCTTGTAG AGACTCTTTTG- $3^{\prime}$ ) and in exon 4 (reverse primer: $5^{\prime}$-CCTCATCATGGA AAGTGTGG-3') (Supplementary Fig. 4a). Gapdh was amplified using forward primer $\left(5^{\prime}\right.$-AGAACATCATCCCTGCATCC- $\left.3^{\prime}\right)$ and reverse primer (5'-CACAT TGGGGGTAGGAACAC- $3^{\prime}$ ) and used for normalization between samples. For senescence-associated markers, following primers were used: $p 16^{I n k 4 a}$ forward, $5^{\prime}$-CCCAACGCCCCGAACT- $3^{\prime} ; p 16^{\text {Ink4a }}$ reverse, $5^{\prime}$-GCAGAAGAGCTGCTA CGTGAA-3'; $p 19^{A R F}$ forward, $5^{\prime}$-AACTCTTTCGGTCGTACCCC-3'; $19^{A R F}$ reverse, 5'-GCGTGCTTGAGCTGAAGCTA-3'; Pail forward, 5'-TCAGAGCA ACAAGTTCAACTACACTGAG-3'; Pai 1 reverse $5^{\prime}$-CCCACTGTCAAGGCTCC ATCACTTGCCCCA-3'; Il forward, $5^{\prime}$-GACAACTTTGGCATTGTGG-3'; Il6 reverse, 5'-ATGCAGGGATGATGTTCTG-3'; Gapdh forward, 5'-ACCACAGTC CATGCCATCAC-3'; Gapdh reverse, 5'-TCCACCACCCTGTTGCTGTA-3'.

\section{References}

1. Zeman, M. K. \& Cimprich, K. A. Causes and consequences of replication stress. Nat. Cell Biol. 16, 2-9 (2014).

2. Negrini, S., Gorgoulis, V. G. \& Halazonetis, T. D. Genomic instability-an evolving hallmark of cancer. Nat. Rev. Mol. Cell Biol. 11, 220-228 (2010).

3. Vijg, J. \& Suh, Y. Genome instability and aging. Annu. Rev. Physiol. 75, 645-668 (2013).

4. Flach, J. et al. Replication stress is a potent driver of functional decline in ageing haematopoietic stem cells. Nature 512, 198-202 (2014).

5. Murga, M. et al. A mouse model of ATR-Seckel shows embryonic replicative stress and accelerated aging. Nat. Genet. 41, 891-898 (2009).

6. Ruzankina, Y. et al. Deletion of the developmentally essential gene ATR in adult mice leads to age-related phenotypes and stem cell loss. Cell Stem Cell $\mathbf{1}$, 113-126 (2007).

7. Chang, D. J. \& Cimprich, K. A. DNA damage tolerance: when it's OK to make mistakes. Nat. Chem. Biol. 5, 82-90 (2009).

8. Sale, J. E., Lehmann, A. R. \& Woodgate, R. Y-family DNA polymerases and their role in tolerance of cellular DNA damage. Nat. Rev. Mol. Cell Biol. 13, 141-152 (2012).

9. Centore, R. C., Yazinski, S. A., Tse, A. \& Zou, L. Spartan/C1orf124, a reader of PCNA ubiquitylation and a regulator of UV-induced DNA damage response. Mol. Cell 46, 625-635 (2012).

10. Ghosal, G., Leung, J. W., Nair, B. C., Fong, K. W. \& Chen, J. Proliferating cell nuclear antigen (PCNA)-binding protein C1orf124 is a regulator of translesion synthesis. J. Biol. Chem. 287, 34225-34233 (2012).

11. Machida, Y., Kim, M. S. \& Machida, Y. J. Spartan/C1orf124 is important to prevent UV-induced mutagenesis. Cell Cycle 11, 3395-3402 (2012).

12. Davis, E. J. et al. DVC1 (Clorf124) recruits the p97 protein segregase to sites of DNA damage. Nat. Struct. Mol. Biol. 19, 1093-1100 (2012).

13. Mosbech, A. et al. DVC1 (C1orf124) is a DNA damage-targeting p97 adaptor that promotes ubiquitin-dependent responses to replication blocks. Nat. Struct. Mol. Biol. 19, 1084-1092 (2012).

14. Juhasz, S. et al. Characterization of human Spartan/Clorf124, an ubiquitinPCNA interacting regulator of DNA damage tolerance. Nucleic Acids Res. 40, 10795-10808 (2012).

15. Kim, M. S. et al. Regulation of error-prone translesion synthesis by Spartan/ C1orf124. Nucleic Acids Res. 41, 1661-1668 (2013).

16. Hendzel, M. J. et al. Mitosis-specific phosphorylation of histone H3 initiates primarily within pericentromeric heterochromatin during G2 and spreads in an ordered fashion coincident with mitotic chromosome condensation. Chromosoma 106, 348-360 (1997).

17. Juan, G. et al. Histone $\mathrm{H} 3$ phosphorylation and expression of cyclins A and B1 measured in individual cells during their progression through G2 and mitosis. Cytometry 32, 71-77 (1998).

18. Rogakou, E. P., Pilch, D. R., Orr, A. H., Ivanova, V. S. \& Bonner, W. M. DNA double-stranded breaks induce histone H2AX phosphorylation on serine 139. J. Biol. Chem. 273, 5858-5868 (1998).
19. Fenech, M. et al. Molecular mechanisms of micronucleus, nucleoplasmic bridge and nuclear bud formation in mammalian and human cells. Mutagenesis 26, 125-132 (2011).

20. Harrigan, J. A. et al. Replication stress induces 53BP1-containing OPT domains in G1 cells. J. Cell Biol. 193, 97-108 (2011).

21. Lukas, C. et al. 53BP1 nuclear bodies form around DNA lesions generated by mitotic transmission of chromosomes under replication stress. Nat. Cell Biol. 13, 243-253 (2011).

22. Dawlaty, M. M. \& van Deursen, J. M. Gene targeting methods for studying nuclear transport factors in mice. Methods 39, 370-378 (2006).

23. Baker, D. J. et al. BubR1 insufficiency causes early onset of aging-associated phenotypes and infertility in mice. Nat. Genet. 36, 744-749 (2004).

24. Baker, D. J. et al. Early aging-associated phenotypes in Bub3/Rael haploinsufficient mice. J. Cell Biol. 172, 529-540 (2006).

25. Hasty, P., Campisi, J., Hoeijmakers, J., van Steeg, H. \& Vijg, J. Aging and genome maintenance: lessons from the mouse? Science 299, 1355-1359 (2003).

26. Baker, D. J. et al. Opposing roles for p16Ink4a and p19Arf in senescence and ageing caused by BubR1 insufficiency. Nat. Cell Biol. 10, 825-836 (2008).

27. Hendel, A. et al. PCNA ubiquitination is important, but not essential for translesion DNA synthesis in mammalian cells. PLoS Genet. 7, e1002262 (2011).

28. Bemark, M., Khamlichi, A. A., Davies, S. L. \& Neuberger, M. S. Disruption of mouse polymerase zeta $(\operatorname{Rev} 3)$ leads to embryonic lethality and impairs blastocyst development in vitro. Curr. Biol. 10, 1213-1216 (2000).

29. Esposito, G. et al. Disruption of the Rev3l-encoded catalytic subunit of polymerase zeta in mice results in early embryonic lethality. Curr. Biol. 10, $1221-1224$ (2000).

30. Wittschieben, J. et al. Disruption of the developmentally regulated Rev3l gene causes embryonic lethality. Curr. Biol. 10, 1217-1220 (2000).

31. Kajiwara, K. et al. Sez4 gene encoding an elongation subunit of DNA polymerase zeta is required for normal embryogenesis. Genes Cells 6, 99-106 (2001).

32. Van Sloun, P. P. et al. Involvement of mouse Rev3 in tolerance of endogenous and exogenous DNA damage. Mol. Cell. Biol. 22, 2159-2169 (2002).

33. Lange, S. S., Wittschieben, J. P. \& Wood, R. D. DNA polymerase zeta is required for proliferation of normal mammalian cells. Nucleic Acids Res. 40, 4473-4482 (2012).

34. Bergoglio, V. et al. DNA synthesis by Pol eta promotes fragile site stability by preventing under-replicated DNA in mitosis. J. Cell Biol. 201, 395-408 (2013).

35. Betous, R. et al. Role of TLS DNA polymerases eta and kappa in processing naturally occurring structured DNA in human cells. Mol. Carcinog. 48, 369-378 (2009).

36. Rey, L. et al. Human DNA polymerase eta is required for common fragile site stability during unperturbed DNA replication. Mol. Cell. Biol. 29, 3344-3354 (2009).

37. Walsh, E., Wang, X., Lee, M. Y. \& Eckert, K. A. Mechanism of replicative DNA polymerase delta pausing and a potential role for DNA polymerase kappa in common fragile site replication. J. Mol. Biol. 425, 232-243 (2013).

38. Lopez-Otin, C., Blasco, M. A., Partridge, L., Serrano, M. \& Kroemer, G. The hallmarks of aging. Cell 153, 1194-1217 (2013).

39. Garinis, G. A., van der Horst, G. T., Vijg, J. \& Hoeijmakers, J. H. DNA damage and ageing: new-age ideas for an age-old problem. Nat. Cell Biol. 10, 1241-1247 (2008).

40. Lessel, D. et al. Mutations in SPRTN cause early onset hepatocellular carcinoma, genomic instability and progeroid features. Nat. Genet. 46, 1239-1244 (2014).

41. Ventura, A. et al. Restoration of p53 function leads to tumour regression in vivo. Nature 445, 661-665 (2007).

42. van Deursen, J., Boer, J., Kasper, L. \& Grosveld, G. G2 arrest and impaired nucleocytoplasmic transport in mouse embryos lacking the proto-oncogene CAN/Nup214. EMBO J. 15, 5574-5583 (1996).

43. Baker, D. J. et al. Clearance of p16Ink4a-positive senescent cells delays ageingassociated disorders. Nature 479, 232-236 (2011).

44. Hahn, W. C. et al. Enumeration of the simian virus 40 early region elements necessary for human cell transformation. Mol. Cell. Biol. 22, 2111-2123 (2002).

45. Barclay, W. W. \& Cramer, S. D. Culture of mouse prostatic epithelial cells from genetically engineered mice. Prostate 63, 291-298 (2005).

46. Liu, X. et al. ROCK inhibitor and feeder cells induce the conditional reprogramming of epithelial cells. Am. J. Pathol. 180, 599-607 (2012).

47. Kannouche, P. L., Wing, J. \& Lehmann, A. R. Interaction of human DNA polymerase eta with monoubiquitinated PCNA: a possible mechanism for the polymerase switch in response to DNA damage. Mol. Cell 14, 491-500 (2004). 


\section{Acknowledgements}

We thank the Mayo Clinic Transgenic and Knockout Core for generating Sprtn-targeted mice and Cytogenetics Core for providing chromosome breakage analysis. We thank Scott H. Kaufmann and Larry M. Karnitz for critical reading of the manuscript. This work was supported by American Cancer Society Research Scholar Grant, NIH R01CA181178 and the Minnesota Partnership for Biotechnology and Medical Genomics (all to Y.J.M.).

\section{Author contributions}

Y.J.M. directed and designed the study. M.K. generated and characterized Sprtn knockout and hypomorphic mice and isolated MEFs. R.S.M. and Y.M. analysed the phenotypes of conditional Sprtn knockout in MEFs. L.A.M. isolated and characterized blastocysts and performed chromosome counts. D.J.B. and B.C. analysed Sprtn hypomorphic mice for ageing-associated phenotypes. K.B.J. performed isolation, culture and karyotyping of lung fibroblasts and prostate epithelial cells. R.S.M., M.K., J.M.v.D. and Y.J.M. wrote the manuscript with contributions from L.A.M. and D.J.B.

\section{Additional information}

Supplementary Information accompanies this paper at http://www.nature.com/ naturecommunications

Competing financial interests: The authors declare no competing financial interests.

Reprints and permission information is available online at http://npg.nature.com/ reprintsandpermissions/

How to cite this article: Maskey, R. S. et al. Spartan deficiency causes genomic instability and progeroid phenotypes. Nat. Commun. 5:5744 doi: 10.1038/ncomms6744 (2014).

(c) (i) This work is licensed under a Creative Commons Attribution 4.0 International License. The images or other third party material in this article are included in the article's Creative Commons license, unless indicated otherwise in the credit line; if the material is not included under the Creative Commons license, users will need to obtain permission from the license holder to reproduce the material. To view a copy of this license, visit http://creativecommons.org/licenses/by/4.0/ 